\title{
In Vivo Assessment of Glutamine Anaplerosis into the TCA Cycle in Human Pre-malignant and Malignant Clonal Plasma Cells
}

\section{Wilson Gonsalves ( $\nabla$ gonsalves.wilson@mayo.edu )}

Mayo Clinic Rochester: Mayo Clinic Minnesota https://orcid.org/0000-0001-6890-969X Jin Sung Jang

Mayo Clinic Rochester: Mayo Clinic Minnesota

\section{Erik Jessen}

Mayo Clinic Rochester: Mayo Clinic Minnesota

Taro Hitosugi

Mayo Clinic Rochester: Mayo Clinic Minnesota

\section{Laura Evans}

Mayo Clinic Rochester: Mayo Clinic Minnesota

\section{Dragan Jevremovic}

Mayo Clinic Rochester: Mayo Clinic Minnesota

\section{Xuan-Mai Petterson}

Mayo Clinic Rochester: Mayo Clinic Minnesota Alexander Graham Bush

Mayo Clinic Rochester: Mayo Clinic Minnesota Jaimee Gransee

Mayo Clinic Rochester: Mayo Clinic Minnesota Emilie I Anderson

Mayo Clinic Rochester: Mayo Clinic Minnesota Shaji K Kumar

Mayo Clinic Rochester: Mayo Clinic Minnesota

K. Sreekumaran Nair

Mayo Clinic Rochester: Mayo Clinic Minnesota

\section{Research}

Keywords: stable isotope metabolomics, plasma cell malignancies, myeloma, glutamine

Posted Date: October 22nd, 2020

DOI: https://doi.org/10.21203/rs.3.rs-93939/v1 
License: (c) (i) This work is licensed under a Creative Commons Attribution 4.0 International License. Read Full License

Version of Record: A version of this preprint was published at Cancer \& Metabolism on December 11th, 2020. See the published version at https://doi.org/10.1186/s40170-020-00235-4. 
1 In Vivo Assessment of Glutamine Anaplerosis into the TCA Cycle in Human Pre-

2 malignant and Malignant Clonal Plasma Cells

3

4 Wilson I. Gonsalves ${ }^{1}$, Jin Sung Jang², Erik Jessen ${ }^{3}$, Taro Hitosugi ${ }^{4}$, Laura A. Evans ${ }^{1}$, Dragan

5 Jevremovic ${ }^{2}$, Xuan-Mai Pettersson, Alexander Graham Bush5, Jaimee Gransee ${ }^{5}$, Emilie I.

6 Anderson $^{1}$, Shaji K. Kumar ${ }^{1}$ and K. Sreekumaran Nair ${ }^{6}$

7

8 1Division of Hematology, Mayo Clinic, Rochester, MN, USA

$9 \quad$ 2Department of Laboratory Medicine and Pathology, Mayo Clinic, Rochester, MN, USA

10 3Department of Health Service Research, Mayo Clinic, Rochester, MN, USA

$11{ }^{4}$ Department of Oncology, Mayo Clinic, Rochester, MN, USA

$12{ }^{5}$ Mayo Clinic Metabolomics Core, Mayo Clinic, Rochester, MN, USA

$13{ }^{6}$ Division of Endocrinology 6 , Mayo Clinic, Rochester, MN, USA

14 Submitting/Corresponding author:

15 Wilson I. Gonsalves MD,

16 Mayo Clinic, Division of Hematology,

17200 First Street SW, Rochester, MN 55905, USA.

18 Tel no: 507-284-2511

19 Email: gonsalves.wilson@mayo.edu

20

21 Short Title: Glutamine Anaplerosis in Bone Marrow Plasma Cells

22 Word Count: Abstract (242 words), Text (5,236 words)

23 Tables: 3; Figures: 5 


\section{Key points:}

25 - Glutamine anaplerosis into the TCA cycle is relatively higher in malignant bone marrow 26 plasma cells compared to pre-malignant plasma cells.

27 - Quantitative levels of TCA cycle intermediates differentiate between MGUS and MM bone 28 marrow microenvironments while reflecting their clonal plasma cell burden.

29

30 Key words: stable isotope metabolomics, plasma cell malignancies, myeloma, glutamine 31

32

33

34

35

36

37

38

39

40

41

42

43

44

45

46

47 

64 from MGUS patients.

\section{ABSTRACT}

Background: Overexpression of c-Myc is required for the progression of pre-malignant plasma cells in monoclonal gammopathy of undetermined significance (MGUS) to malignant plasma cells in multiple myeloma (MM). c-Myc also increases glutamine anaplerosis into the tricarboxylic acid (TCA) cycle within cancer cells. Whether increased glutamine anaplerosis is associated with the progression of pre-malignant to malignant plasma cells is unknown.

Methods: Human volunteers ( $\mathrm{N}=7)$ and patients with MGUS $(\mathrm{N}=11)$ and MM $(\mathrm{N}=12)$ were prospectively recruited to undergo an intravenous infusion of ${ }^{13} \mathrm{C}$-labelled glutamine followed by a bone marrow aspiration to obtain bone marrow cells and plasma.

Results: Despite notable heterogeneity, stable isotope resolved metabolomics (SIRM) revealed that the mean ${ }^{13} \mathrm{C}$-labelled glutamine anaplerosis into the TCA cycle was higher in malignant compared to pre-malignant bone marrow plasma cells relative to the remainder of their paired bone marrow mononuclear cells. RNA sequencing demonstrated a higher relative mRNA expression of c-Myc and glutamine transporters such as ASCT2 and SN2 in malignant compared to pre-malignant bone marrow plasma cells. Finally, higher quantitative levels of TCA cycle intermediates in the bone marrow plasma differentiated MM

Conclusion: Measurement of the in vivo activity of glutamine anaplerosis into the TCA cycle provides novel insight into the metabolic changes associated with the transformation of premalignant plasma cells in MGUS to malignant plasma cells in MM.

Trial registration: NCT03384108 and NCT03119883.

69 Funding: K23CA218742, U24DK100469, UL1TR000135, Fraternal Order of the Eagles 70 Grant, Predolin Foundation and the Marion Schwartz Foundation. 


\section{INTRODUCTION}

72 Multiple myeloma (MM) is the second most common hematological malignancy in the US

73 with over 20,000 new MM patients being diagnosed each year.[1] This malignant plasma cell

74 disorder is associated with devastating end-organ damage such as bone destruction, renal

75 failure, anemia, and hypercalcemia.[2] Despite improvements in survival with the advent of

76 novel therapies[3-5], MM remains mostly incurable with a median survival of only 5 to 7

77 years.[6] Thus, identifying novel targets in clonal plasma cells (cPCs) from MM that can be

78 exploited for clinical purposes either for early diagnosis or therapeutic purposes remain

79 critical.

80 Malignant cells have altered cellular metabolism in order to meet increased

81 requirements for nutrients and energy.[7] Although up regulation of aerobic glycolysis (the

82 "Warburg effect") is common in most cancer cells, it is insufficient to support their increased

83 anabolic metabolism.[8] The energy/nutrient deficit is overcome mostly by the tricarboxylic

84 acid (TCA) cycle whereby TCA intermediates serve as precursors for the biosynthesis of

85 fatty acids, nucleic acids, and proteins, and need constant replenishment.[9] Glutamine

86 anaplerosis or entry into the TCA cycle[10] via the formation of glutamate from glutamine

87 and the subsequent formation of alpha-ketoglutarate from glutamate is one method of 88 replenishing the TCA cycle intermediates.[11]

89 Overexpression of the transcription factor c-Myc is required for the pathogenesis of

malignant plasma cells in MM from their precursor state of pre-malignant plasma cells in

91 monoclonal gammopathy of undetermined significance (MGUS). $c$-Myc activation signatures

92 are mostly absent in pre-malignant plasma cells derived from patients with MGUS, whereas

$9370 \%$ of new MM patients have up-regulated $c-M y c$ activation signatures in their malignant 
94 plasma cells.[12] Furthermore, $M y c$ activation in germinal center B cells leads to formation

95 of sporadic MM tumors in $\mathrm{Vk}^{*} \mathrm{MYC}$ mice suggesting its critical role for the progression into 96 MM.[13] Interestingly, c-Myc also promotes transcription of glutamine transporters ASCT2 97 and SN2 on cell membranes [14] and upregulates GLS1 protein expression to increase 98 conversion of glutamine to glutamate by suppressing mIR23a/b (both being negative regulators of GLS).[15] Thus, c-Myc leads to increased uptake of glutamine in cells and also 100 increases the conversion of glutamine into glutamate which then enters into the TCA cycle 101 (i.e. glutamine anaplerosis) in mitochondria.[16] However, it remains to be determined 102 whether the level of glutamine anaplerosis into the TCA cycle is higher in malignant plasma 103 cells of the bone marrows of MM patients relative to their adjacent bone marrow 104 mononuclear cells is unknown. And if so, it is uncertain if increasing glutamine anaplerosis 105 activity into the TCA cycle is associated with the progression of pre-malignant plasma cells 106 in MGUS to malignant plasma cells in MM.

107 There is a gap in knowledge of the activity of metabolic pathways in pre-malignant 108 plasma cells from MGUS due to the lack of adequate in vitro models, as human myeloma cell 109 lines (HMCLs) only represent malignant plasma cells from patients with end-stage MM. In 110 addition, cell culture artifacts from in vitro approaches remain a major barrier in the study 111 of tumor metabolism in humans.[17] To overcome these barriers, this study compared the 112 activity of glutamine anaplerosis into the TCA cycle in pre-malignant plasma cells and 113 malignant plasma cells obtained from MGUS and MM patients respectively to their paired 114 remainder of the bone marrow mononuclear cells by using in vivo stable isotope-resolved 115 metabolomics (SIRM) to trace the incorporation of ${ }^{13} \mathrm{C}$ glutamine into the intermediates of 116 the TCA cycle. 
117 RESULTS

118 Glutamine anaplerosis into the TCA cycle is present in human myeloma cell lines.

119 The HMCLs, RPMI-8226 and MM1S, like most cancer cell lines require glutamine 120 supplementation in the cell culture media for optimal proliferation and survival. Our prior 121 study demonstrated glutamine as being the preferred supplier of carbon substrate for the 122 TCA cycle intermediates via its anaplerosis into the TCA cycle in comparison to glucose 123 oxidation when assessed over a time period of 12 hours.[18] The expected isotopomer 124 labeling pattern of TCA cycle intermediates when $\left[{ }^{13} \mathrm{C}_{5}\right]$-glutamine undergoes anaplerosis 125 into the TCA cycle is depicted in Supplementary Figure 1. However, this incorporation of $126{ }^{13} \mathrm{C}$ into the TCA cycle intermediates in HMCLs is rapid as was observed when RPMI-8226 127 and MM1S HMCLs were cultured for only 60 minutes in RPMI-1640 media containing 2 mM 128 of glutamine of which only $5 \%$ was enriched with $\left[{ }^{13} \mathrm{C}_{5}\right]$-glutamine (Supplementary Figure 129 2). This rapid uptake of glutamine is not unexpected given the very high proliferation and 130 short doubling time of HMCLs that require nutrients like glutamine for biomass, energy and 131 redox homeostasis. However, recent studies have demonstrated that the extent of a cancer 132 cell line's dependence on glutamine anaplerosis may differ based on its environmental 133 context such as the level of cystine.[19] Thus, whether our in vitro observation of glutamine 134 anaplerosis into the TCA cycle of HMCLs is observed in humans in vivo in bone marrow pre135 malignant and malignant plasma cells and their paired remainder of the bone marrow 136 mononuclear cells is unclear. 


\section{Intravenous infusion of ${ }^{13} \mathrm{C}$-labelled glutamine in human volunteers is feasible, safe} and subsequently detectable in non-malignant bone marrow plasma cells
A total of seven healthy volunteers were prospectively recruited to participate in a pilot study evaluating the feasibility and safety of assessing the in vivo utilization of glutamine by their bone marrow plasma cells. All volunteers, in the fasting state, received an infusion of $\left[5^{-13} \mathrm{C}\right]$-glutamine as a bolus dose over 5 minutes followed by a continuous infusion of this agent over 60 minutes prior to undergoing a bone marrow aspiration to harvest bone marrow plasma cells with the infusion ending immediately thereafter (Figure 1A). The clinical characteristics of these seven volunteers, the bolus and continuous infusion dosages of ${ }^{5-13} \mathrm{C}$-glutamine infused and their pre- and post-infusion serum ammonia and blood urea nitrogen levels which were measured to assess for metabolic toxicities are listed in Table 1. The infusion generated a persistent $(m+1)$ glutamine enrichment in the peripheral blood ranging from $4 \%$ - 10\% within the first fifteen minutes of the continuous infusion (Figure 1B). The ${ }^{5-13} \mathrm{C}$-glutamine enrichment was relatively higher in bone marrow plasma compared to paired peripheral blood plasma after 60 minutes of the ${ }^{5-13} \mathrm{C}$-glutamine infusion (Figure 1C). We next performed a comparison of sorted CD138+ (non-malignant plasma cells) and paired CD138- cells (remainder of the bone marrow mononuclear cells) for the enrichment of ${ }^{13} \mathrm{C}$ in their intracellular TCA cycle intermediates. The cell sorting process for bone marrow mononuclear cells based on CD138 expression of four of the seven volunteers were inadequate for analysis due to technical processing errors incurred initially in this study. Thus, sorted cells were available only in three volunteers, and the enrichment of ${ }^{13} \mathrm{C}$ in their intracellular TCA cycle intermediates was normalized to the steady state ${ }^{13} \mathrm{C}$ $(m+1)$ glutamine enrichment in their respective bone marrow plasma samples. Figure 1D 
162 shows the observed enrichment of ${ }^{13} \mathrm{C}$ in the intracellular intermediates from the first turn

163 of the TCA cycle in CD138+ plasma cells and their paired CD138- bone marrow mononuclear

164 cells. This demonstrated the feasibility of the in vivo SIRM methods for assessing glutamine 165 anaplerosis into the TCA cycle in bone marrow plasma cells and the remainder of their paired 166 bone marrow mononuclear cells.

Glutamine anaplerosis into the TCA cycle in pre-malignant and malignant plasma cells relative to their paired bone marrow mononuclear cells

170 We next evaluated the amount of glutamine anaplerosis into the TCA cycle of pre-malignant 171 and malignant plasma cells from MGUS and MM patients respectively relative to the 172 remainder of their paired bone marrow mononuclear cells. A total of eleven MGUS and 173 twelve MM patients were prospectively enrolled on this study. To improve the mass174 spectrometry (MS) detection of the various TCA cycle isotopologues of interest, we used an 175 intravenous infusion of $\left[{ }^{13} \mathrm{C}_{5}\right]$-glutamine (i.e. as it would form $\mathrm{m}+5$ and $\mathrm{m}+4$ isotopomers in 176 the first turn of the TCA cycle) instead of the previously utilized ${ }^{5-13} \mathrm{C}$-glutamine (which 177 forms $\mathrm{m}+1$ isotopomers in the first turn of the TCA cycle). $\left[{ }^{13} \mathrm{C} 5\right]$-glutamine was administered 178 as a bolus dose ( $4 \mathrm{mg} / \mathrm{kg}$ ) over 5 minutes followed by a continuous infusion ( $4 \mathrm{mg} / \mathrm{kg} / \mathrm{hr}$ ) 179 over 60 minutes prior to undergoing a bone marrow aspiration to harvest bone marrow 180 plasma cells with the infusion ending immediately thereafter. The clinical characteristics of 181 these MGUS and MM patients and their corresponding bolus and continuous infusion 182 dosages of $\left[{ }^{13} \mathrm{C}_{5}\right]$-glutamine are listed in Table 2 and Table 3 respectively. The infusion 183 generated a $(m+5)$ glutamine enrichment ranging from $3 \%-7 \%$ in the bone marrow plasma 184 after completing 60 minutes of the continuous infusion which was similar between MGUS 
and MM patients (Figure 2A). Upon acquiring the bone marrow aspirate sample, subsequent processing was performed to yield bone marrow CD138+ cells (pre-malignant or malignant plasma cells) and paired CD138- (remainder of the bone marrow mononuclear cells) from each aspirate sample. The cell sorting process for bone marrow mononuclear cells based on CD138 expression yielded sufficient clonal pre-malignant plasma cells in only ten of the eleven MGUS patients and sufficient clonal malignant plasma cells in only eleven of the twelve MM patients. As a result, isotopomer data evaluating the incorporation of ${ }^{13} \mathrm{C}$ from glutamine into the TCA cycle intermediates of CD138+ and their paired CD138- cells was available for assessment in only ten MGUS and eleven MM patients (Figure 2B). The mean ${ }^{13} \mathrm{C}$ labelling of the TCA cycle intermediates (glutamate, citrate, fumarate, malate and aspartate) derived from $\left[{ }^{13} \mathrm{C}_{5}\right]$-glutamine anaplerosis into the first turn of the TCA cycle were higher in CD138+ malignant plasma cells from MM patients compared to the remainder of their paired CD138- mononuclear cells. In contrast, the mean ${ }^{13} \mathrm{C}$ labelling of the TCA cycle intermediates derived from $\left[{ }^{13} \mathrm{C}_{5}\right]$-glutamine anaplerosis into the TCA cycle were not significantly higher in CD138+ pre-malignant plasma cells from MGUS patients compared to the remainder of their paired CD138- mononuclear cells except for the metabolite aspartate. To better understand the observed differences in the mean ${ }^{13} \mathrm{C}$ labelling of the TCA cycle intermediates between the two disease groups, the ${ }^{13} \mathrm{C}$ labelling of individual TCA cycle intermediates were also evaluated in each individual MGUS and MM patient by assessing their fractional ${ }^{13} \mathrm{C}$ enrichment (i.e. ratio of ${ }^{13} \mathrm{C}$ enrichment of a TCA metabolite in CD138+ cells/ CD138- cells such that a ratio of $>1$ reflects higher ${ }^{13} \mathrm{C}$ labelling of the specific metabolite in CD138+ cells). This analytical approach demonstrated notable variability in the fractional ${ }^{13} \mathrm{C}$ enrichment of individual TCA cycle intermediates within pre-malignant 
208 and malignant CD138+ plasma cells obtained from MGUS and MM patients respectively

209 (Figure 2C). Thus, the glutamine anaplerosis into the TCA cycle based on the mean ${ }^{13} \mathrm{C}$ 210 labelling of the TCA metabolites was higher in malignant than pre-malignant CD138+ bone 211 marrow plasma cells when compared to the remainder of their paired CD138- bone marrow 212 mononuclear cells. However, this increased glutamine anaplerosis into the TCA cycle in 213 CD138+ malignant plasma cells compared to the remainder of their paired CD138214 mononuclear cells was not uniformly observed in all MM patients. On the contrary, it was 215 also observed even in few MGUS patients and their CD138+ pre-malignant plasma cells when 216 compared to the remainder of their paired CD138- mononuclear cells suggesting significant 217 heterogeneity in the activity of this pathway among the pre-malignant and malignant 218 CD138+ plasma cells from MGUS and MM patients respectively. We don't have sufficient 219 follow-up data to assess whether those MGUS patients who demonstrated increased 220 fractional ${ }^{13} \mathrm{C}$ enrichment of the TCA cycle intermediates in their CD138+ pre-malignant 221 plasma cells when compared to the remainder of their paired CD138- mononuclear cells 222 were more likely to develop MM sooner compared to the remainder of the MGUS patients.

224 Transcriptomic analysis of the expression of c-Myc and glutamine transporters on cell 225 membranes in pre-malignant or malignant plasma cells and their paired remainder 226 of bone marrow mononuclear cells

227 Transcriptional upregulation of genes involved in glutamine anaplerosis is one of the 228 possible explanations for the differences in glutamine anaplerosis activity to exist between 229 any two groups if present. Our apriori hypothesis was that increased $c$-Myc expression leads 230 to the progression of pre-malignant plasma cells in MGUS to malignant plasma cells in MM 
231 with a resultant increase in glutamine anaplerosis into the TCA cycle that is facilitated by the

232 overexpression of GLS1 that converts glutamine to glutamate as well as by overexpression

233 of the glutamine cell membrane transporters ASCT2 and SN2. Therefore, we examined the

234 RNA expression profile of CD138+ pre-malignant and malignant plasma cells as well as their

235 paired CD138- mononuclear cells from the bone marrows of MM and MGUS patients using

236 RNA sequencing. Sufficient RNA was obtained from six patients with MGUS and ten patients

237 with MM. A total of 2300 genes were determined to be differentially expressed between the

238 malignant and pre-malignant CD138+ plasma cells from MM and MGUS groups respectively

239 of which 799 genes were overexpressed and 1501 were under expressed. Hierarchical

240 clustering analysis was performed demonstrating the overall differential expression of genes

241 between the two groups (Figure 3A). As expected, there was an increased relative

242 expression of c-Myc mRNA in CD138+ malignant plasma cells from MM compared to CD138+

243 pre-malignant plasma cells from MGUS as well as an increase in the mRNA expression of

244 glutamine importers such as ASCT2 and SN2 (Figure 3B). However, the expression of GLS1

245 was similar between the CD138+ malignant and pre-malignant plasma cells. There was also

246 an increased relative mRNA expression of c-Myc, GLS1, ASCT2 and SN2 in CD138+ malignant

247 plasma cells compared to their paired CD138- mononuclear cells in MM patients supporting

248 the previous observation of a higher mean ${ }^{13} \mathrm{C}$ labelling of the TCA cycle intermediates

249 (glutamate, citrate, fumarate, malate and aspartate) in CD138+ malignant plasma cells from

250 MM patients compared to their paired CD138- mononuclear cells. Interestingly, the relative

251 mRNA expression of c-Myc, GLS1 and ASCT2 in CD138+ pre-malignant plasma cells was also

252 higher than their paired CD138- mononuclear cells in MGUS patients although not to the

253 same extent as seen in MM patients (Supplementary Table 1). This suggests that even at 
254 the MGUS stage, there may be a preferential utilization of glutamine by CD138+ pre255 malignant plasma cells over their paired CD138- mononuclear cells. It also supports the 256 previous observation of higher fractional ${ }^{13} \mathrm{C}$ enrichment of the TCA cycle intermediates in 257 the CD138+ pre-malignant plasma cells from individual MGUS patients compared to their 258 paired CD138- mononuclear cells.

259

Quantitative levels of TCA cycle intermediates in the bone marrow plasma of patients with MGUS and MM

262 Though heterogenous, since the average in vivo activity of glutamine anaplerosis into the 263 TCA cycle was different between CD138+ malignant plasma cells from MM patients and their 264 paired CD138- bone marrow mononuclear cells, we assessed the absolute quantification of 265 the concentrations of these TCA cycle intermediates in the bone marrow and peripheral 266 blood plasma of these MM patients and compared them to those from the MGUS patients. 267 Interestingly, there were significantly higher levels of glutamate and aspartate and lower 268 levels of glutamine in the bone marrow plasma of MM patients compared to that obtained 269 from MGUS patients (Figure 4A). In contrast, there were no significant differences in the 270 levels of TCA cycle intermediates in the peripheral blood plasma of MM patients compared 271 to MGUS patients (Figure 4B). One likely explanation for this difference is that the bone 272 marrow plasma is the closest to representing the surrounding microenvironment of the pre273 malignant and malignant CD138+ plasma cells as well as their CD138- mononuclear cells 274 unlike peripheral blood plasma. It is possible that either the intracellular differences in the 275 levels of the TCA cycle intermediates between pre-malignant and malignant bone marrow 276 CD138+ plasma cells or the differences between the CD138- bone marrow mononuclear cells 
277 from MGUS and MM patients are more likely to be captured from extracellular assessments

278 in the bone marrow plasma rather than the peripheral blood plasma. Interestingly, in a cross

279 comparison assessment of the bone marrow plasma concentrations of glutamate and 280 aspartate between the previously described human volunteers and the patients with MGUS 281 and MM, the levels of glutamate and aspartate in MGUS patients was akin to that observed in 282 the human volunteers which together were both lower than that detected in MM patients 283 (Figure 4C). Furthermore, the levels of both these TCA cycle metabolites directly correlated 284 to the percentage of CD138+ plasma cells present in their bone marrows (Figure 4D).

285 Finally, among the MM patients enrolled on this study, there were two patients (MM\#2 and 286 MM\#7) who had distinct clinical phenotypes. The first patient (MM\#2) had 287 relapsed/refractory primary plasma cell leukemia with an extensive amount of bone 288 marrow infiltration with malignant plasma cells as well as a high number of circulating 289 malignant plasma cells (Figure 5A). Interestingly, this patient had the lowest $(m+5)$ 290 glutamine enrichment in the bone marrow plasma at $\sim 2.85 \%$ compared to the remainder of 291 the MM patients despite receiving the same weight-based dose of the stable isotope infusion. 292 A possible explanation could be that the large number of malignant plasma cells consumed 293 most of the intravenously infused U-13C-glutamine, thus preventing the bone marrow plasma 294 enrichment from getting to higher level as seen with most of the other MM patients. The 295 second patient (MM\#7) had relapsed/refractory MM but all the malignant plasma cells were 296 confined to his chest and mediastinum with no bone marrow involvement in the posterior 297 iliac crest since diagnosis typically seen with the other MM patients (Figure 5B). This patient 298 also had the second lowest $(m+5)$ glutamine enrichment in the bone marrow plasma after 299 MM\#2 at $\sim 3.35 \%$ compared to the remainder of the MM patients. Again, a possible 
300 explanation could be that the presence of several large plasmacytomas comprised of 301 malignant plasma cells in the chest consumed a lot of the intravenously infused $\mathrm{U}-{ }^{13} \mathrm{C}$ 302 glutamine preventing the bone marrow plasma enrichment from getting to a higher level. 303 Furthermore, the concentrations of the TCA cycle intermediate such as glutamate, succinate, 304 fumarate, malate and aspartate were markedly higher in the bone marrow plasma of MM\#2 305 compared to the remainder of the MM patients likely reflecting the extensive malignant 306 plasma cell burden in the posterior iliac crest site of the bone marrow aspiration (Figure 307 5C). In contrast, the concentrations of the TCA cycle intermediate such as glutamate, 308 succinate, and aspartate were markedly lower and the concentration of glutamine was 309 markedly higher in the bone marrow plasma of MM\#7 compared to the remainder of the MM 310 patients likely reflecting the absence of any malignant plasma cells in the posterior iliac crest 311 site of the bone marrow aspiration. 


\section{DISCUSSION}

324 The current study demonstrated the in vivo activity of glutamine anaplerosis into the TCA 325 cycle in pre-malignant and malignant bone marrow plasma cells from patients with MGUS and MM respectively. Here we show that evaluating the differences between the intracellular

327 metabolism of malignant plasma cells and their paired non-malignant mononuclear cells in 328 the bone marrow is feasible and can offer valuable insight into the metabolic transformation 329 of pre-malignant plasma cells in MGUS to malignant plasma cells in MM. Furthermore, this 330 study also demonstrated that the concentrations of TCA cycle metabolites in the extracellular 331 space such as the bone marrow plasma which is akin to the microenvironment reflect the 332 differences between the intracellular metabolism of malignant and pre-malignant plasma 333 cells or possibly even between the remainder of their paired CD138- mononuclear cells.

334 While the glutamine anaplerosis into the TCA cycle based on the mean ${ }^{13} \mathrm{C}$ labelling of the 335 TCA metabolites was higher in malignant compared to pre-malignant CD138+ bone marrow 336 plasma cells relative to the remainder of their paired CD138- bone marrow mononuclear 337 cells (Figure 2B), this was heterogeneously observed among individual MGUS and MM 338 patients (Figure 2C). There were some MGUS patients whose CD138+ pre-malignant plasma 339 cells had higher fractional ${ }^{13} \mathrm{C}$ labelling of their TCA metabolites when compared to the 340 remainder of their paired CD138- mononuclear cells. It would be intriguing if these 341 aforementioned MGUS patients would have a shorter time to progression to MM, however 342 the study follow-up period is not currently sufficient enough to assess this possibility. 343 Nevertheless, this in vivo SIRM approach to assess the activity of other metabolic pathways 344 of interest in addition to glutamine anaplerosis in bone marrow plasma cells remains 345 promising. This is even more applicable in smoldering multiple myeloma (SMM), a more 
346 advanced, asymptomatic clonal plasma cell disorder associated with a higher tumor burden 347 than MGUS, but without the end-organ damage seen in MM.[20] Unlike MGUS, where the risk 348 of progression to MM is $1 \%$ per year, the risk of progression in SMM is heterogeneous and 349 decreases with time $(\sim 10 \% /$ year for the first 5 years, $\sim 3 \% /$ year for the next 5 years, and $350 \sim 1 \% /$ year thereafter).[21] This suggests that SMM is a mix of patients with pre-malignant 351 plasma cells as in MGUS and patients with malignant plasma cells as in MM but who have not 352 yet developed end-organ damage. Some patients with SMM rapidly progress to MM within 353 one to two years of their diagnosis, suggesting that their plasma cells were already malignant 354 and had biologically progressed to MM.[22] However, at diagnosis the stratification of SMM 355 patients is not obvious given the lack of end-organ damage (e.g., bone destruction or renal 356 failure), and no reliable clinical or pathological methods are available to differentiate 357 between pre-malignant plasma cells in MGUS and malignant plasma cells in MM. Adding ${ }^{13} \mathrm{C}$ 358 SIRM profiling of intracellular metabolic pathways to assist in differentiating pre-malignant 359 from malignant plasma cells could bridge this gap and enable early identification of SMM 360 patients at high risk of progression. Clinical benefit of early therapy in SMM patients likely 361 to progress is well documented.[23] Conversely, identification of those SMM patients at low 362 risk of progression to MM reduces anxiety and prevents risk of toxicity from unnecessary 363 intervention.

364 While not unexpected, it was interesting to observe that the relative ${ }^{13} \mathrm{C}$ labelling of the 365 intermediates from the first turn of the TCA cycle in RPMI-8226 and MM1S HMCLs when 366 cultured in media containing 5\% enrichment with $\left[{ }^{13} C_{5}\right]$-glutamine for 60 minutes 367 (Supplementary Figure 2) was higher than observed in the CD138+ malignant plasma cells 368 from MM patients who had similar levels of $\left[{ }^{13} \mathrm{C}_{5}\right]$-glutamine enrichment in their bone 
369 marrow plasma for approximately the same duration (Figure 2B). The very high 370 proliferation and short doubling time of HMCLs compared to most primary CD138+ 371 malignant plasma cells from MM patients is likely one explanation for this difference as 372 HMCLs are typically reflective of disease biology that is most aggressive and derived from 373 MM patients at the end stages of their disease. However, another explanation could be that 374 the differences observed in the extent of glutamine utilization between HMCLs and primary 375 CD138+ malignant plasma cells from MM patients may be based on its environmental 376 context such as ex vivo versus in vivo artifacts assessments.[19] The concentrations of 377 nutrients in cell culture media are not reflective of the true physiological levels experienced 378 by primary CD138+ malignant plasma cells from MM patients.[17] This has major 379 implications when evaluating the potential efficacy of metabolic inhibitors in the pre-clinical 380 setting.

381 The overexpression of glutamine transporters such as ASCT2 and SN2 observed in 382 malignant CD138+ cells compared to the remainder of their paired bone marrow CD138383 mononuclear cells point to their potential as therapeutic targets against glutamine 384 metabolism that are worth investigating in the future in MM models. In fact, Bolzoni et al 385 previously demonstrated the high expression of such glutamine transporters and inhibition 386 of ASCT2 could hinder MM growth in both in vitro and in vivo models.[24] It would be even 387 more intriguing if these transporters could be modulated to prevent the progression of pre388 cursor conditions like MGUS to MM. Finally, it was interesting to observe that the mean ${ }^{13} \mathrm{C}$ 389 labelling of aspartate derived from $\left[{ }^{13} \mathrm{C} 5\right]$-glutamine anaplerosis into the TCA cycle was 390 significantly higher in both CD138+ pre-malignant and malignant plasma cells from MGUS 391 and MM patients respectively when compared to the remainder of their paired CD138- 
392 mononuclear cells. Though not statistically significant, this increased mean ${ }^{13} \mathrm{C}$ labelling of 393 aspartate in the $\mathrm{CD} 138+$ cells derived from ${ }^{5-13} \mathrm{C}$-glutamine was also observed in the 394 volunteer cohort. This supports prior observations of increased glutamine utilization by the 395 TCA cycle to form aspartate in normal human polyclonal plasma cells and is thought to be 396 important in supporting their function of antibody production.[25] Thus, it is likely that since 397 both pre-malignant and malignant CD138+ plasma cells are constantly producing excess 398 monoclonal antibodies, their utilization of glutamine for aspartate production is equally 399 higher than the remainder of their paired CD138- mononuclear cells.

400 There are several limitations to this human study. First, it is not known if isotopic steady 401 state was reached in the fraction of CD138+ and CD138- cells from the bone marrow as this 402 would require multiple sampling of bone marrow during the infusion which was not feasible. 403 However, we not only samples similar time points following isotope infusion but also the 404 analytical approach we used here do not require isotopic steady state as we determined the 405 precursor product relationship by normalizing isotopic enrichment of citric acid metabolites 406 to plasma glutamine enrichment. Second, there is likely significant attrition of the ${ }^{13} \mathrm{C}$ 407 labelling within the fraction of CD138+ and CD138- cells from the bone marrow sample as it 408 undergoes various cell sorting processes. However, it is likely that the tracer and tracee loss 409 occurred similarly such that the enrichment values are indicative of the incorporation of 410 glutamine (via glutamate) into the TCA cycle pathway. Moreover, the normalization 411 procedure of the ${ }^{13} \mathrm{C}$ labelling fractions to the enrichment of the stable isotope in the bone 412 marrow plasma as well as relative comparisons of the CD138+ fractions to their paired 413 CD138- fractions allow for adequate comparisons between different groups like MGUS and 414 MM. Despite these limitations, this study demonstrates the feasibility of gaining insight into 
415 the metabolic underpinnings of MM by evaluating the activity of intracellular metabolic 416 networks in malignant plasma cells and their pre-malignant pre-cursors in the bone marrow 417 via in vivo stable isotope tracing methodologies. Similar human studies utilizing SIRM 418 methods have been performed in various cancers like lung cancer[26-29], kidney cancer[30] 419 and glioblastoma[31] utilizing a variety of different stable isotope tracers to assess 420 intracellular metabolic pathways. In the future, larger studies may not only be undertaken 421 to assess the in vivo measurement of glutamine anaplerosis or even other metabolic 422 pathways as a marker of conversion of MGUS or SMM to MM but also to assess potential 423 effects of molecules that promise to arrest the progression of MGUS or SMM to MM.

424

425

426

427

428

429

430

431

432

433

434

435

436

437 


\section{METHODS}

439 Research protocol for bone marrow assessment of human volunteers and patients with PC 440 disorders

441 All methods carried out in this study were in accordance with relevant guidelines and 442 regulations. Approval for this study (IRB\#: 17-00313) was obtained from the Mayo Clinic 443 IRB in accordance with the federal regulations and the principles of the Declaration of 444 Helsinki. Prospective human volunteers were recruited following local advertisements 445 under the clinical trial NCT03384108. Whereas consecutive patients with MM and MGUS 446 were prospectively recruited in the clinic under the clinical trial NCT03119883. The 447 diagnostic criteria of International Myeloma Working Group (IMWG) were applied to 448 confirm the diagnosis of MGUS and MM. Upon accrual on either study, participants 449 underwent admission to the clinical research and translational unit for performance of the 450 study procedures. The study procedures involved peripheral blood collections at baseline. 451 The next step was to undergo a bolus injection followed by a continuous infusion of either 5$452 \quad{ }^{13} \mathrm{C}$-glutamine (3-4 mg/kg bolus and 3-4 mg/kg/hr continuous infusion) or [13 $\left.\mathrm{C}_{5}\right]$-glutamine 453 (4 mg/kg bolus and $4 \mathrm{mg} / \mathrm{kg} / \mathrm{hr}$ continuous infusion) in the volunteers and MGUS/MM 454 patients respectively. Serial peripheral blood assessments were performed only in the 455 volunteers every 15 minutes upon the start of the continuous infusion to assess the 456 enrichment of $(\mathrm{m}+1)$ glutamine in the peripheral blood. After 60 minutes of receiving the $457{ }^{13} \mathrm{C}$-glutamine infusions, a bone marrow aspiration was performed on the posterior iliac 458 crest and whole bone marrow aspirate samples were collected in cold EDTA tubes for 459 immediate processing. 
462

463

464

465

466

467

468

469

470

$471 \quad$ RNAseq and data analysis

472 Total RNA was extracted from cells and the extracted RNAs were evaluated using a Qubit

473 (Thermo Fisher Scientific, MA, USA) and Agilent 2100 Bioanalyzer (Agilent Technologies, 474 Santa Clara, CA, USA), respectively. The TrueSeq RNA Exome Kit (Illumina, CA, USA) was used 475 to generate the mRNA-Seq library according to the manufacturer's protocol. Constructed 476 libraries were quantified by BioAnalizer 2100 system using the D1000 kit (Agilent) and 477 Qubit dsDNA BR Assay kits (Thermo Fisher Scientific). All libraries were pooled and 478 sequenced 101 bp paired-end reads on Illumina HiSeq 4000. FASTQ files were uploaded into 479 Partek Flow software (Partek Inc., MO, USA), and primary QC was performed. The STAR 480 (2.7.3a) aligner was used to align reads to the human reference genome (hg38). After 481 alignment, the final BAM files were quantified using Partek E/M algorithm [32] by Ensembl 482 annotations (Ensembl Transcripts release 92). DESeq2 package [33] was used to normalize 483 data and determine differential expression of RNA-Seq between the groups. The false 
484 discovery rate (FDR) by Benjamin and Hochberg method was used to adjust for comparison. 485 FDR value less than 0.05 and fold change \pm 2 at raw $P$ value less than 0.05 were considered 486 as a significant change. Hierarchical clustering was performed on the significantly changed 487 genes based on the Euclidean distance and the average linkage clustering algorithm using 488 Partek Flow software.

489

490

Methodology for quantitative assessments of TCA metabolites via GC-MS:

491 Bone marrow plasma and peripheral blood plasma samples were spiked in 15 of internal 492 solution containing $\left[{ }^{13} \mathrm{C}_{5}\right]$-labeled analytes for $2-\mathrm{HG}$, glutamate and $\alpha$-ketoglutarate. The 493 proteins were removed by adding $260 \mu \mathrm{l}$ of chilled methanol and acetonitrile solution to the 494 sample mixture. After drying the supernatant in the speed vacuum, the sample was 495 derivatized with a solution of 0-ethylhydroxylamine in pyridine $(20 \mathrm{mg} / \mathrm{mL})$ for 1 hour at $49635^{\circ} \mathrm{C}$, followed by sylation with MtBSTFA + 1\% tBDMCS for 1 hour at $70{ }^{\circ} \mathrm{C}$ before it was 497 analyzed on an Agilent 5977B GC/MS under electron impact and single ion monitoring 498 conditions. Concentrations of $\alpha$-ketoglutarate (m/z 360.2), 2-HG (m/z 433.2), and glutamate $499(\mathrm{~m} / \mathrm{z} 432.2)$ were measured against a 12-point calibration curves that underwent the same 500 derivatization.

501

502 Gas chromatography-mass spectrometry (GC/MS) based isotopomer analyses

503 Isotopomer analysis of the intracellular and extracellular TCA cycle metabolites from the 504 HMCL cell pellets and spent media respectively were performed using an Agilent 505 Technologies 5977B GC/MS (Agilent Inc, CA, USA). Splitless injections of $1 \mu \mathrm{L}$ aliquots of the 506 derivatized extracts were injected onto a DB5-MS capillary column (30 m x $250 \mu \mathrm{m}$ i.d., 
$507 \quad 0.25 \mu \mathrm{m}$ film thickness; J\&W Scientific, Folson, CA). The mass spectrometer (MS) was 508 operated under electron impact (EI) conditions with selected ion monitoring (SIM). The 509 temperature of the injector was set at $250^{\circ} \mathrm{C}$ and the transfer line to the $\mathrm{MS}$ at $280^{\circ} \mathrm{C}$. Helium 510 was used as the carrier gas at a flow rate of $1 \mathrm{~mL} / \mathrm{min}$. The GC temperature program used 511 was: oven held for $0.5 \mathrm{~min}$ at $120^{\circ} \mathrm{C}$, then increased to $180^{\circ} \mathrm{C}$ at $25^{\circ} \mathrm{C} / \mathrm{min}$, then to $270^{\circ} \mathrm{C}$ at $5126^{\circ} \mathrm{C} / \mathrm{min}$ and finally increased to $325^{\circ} \mathrm{C}$ at $30^{\circ} \mathrm{C} / \mathrm{min}$ with a hold time of $1 \mathrm{~min}$. Data were 513 processed using MassHunter quantitative analysis software version B.08.00 build 8.0.598.0 514 (Agilent Technologies Inc., CA, USA) for integration of peaks and calculation isotopic ratios. 515 SIM was used to monitor the mole percent enrichment for each analyte, such as the 516 fragment (M0) and all labeled mass isotopomer positions (M1, M2, M3 etc.) up to m+2 above 517 the number of carbons in the molecule backbone. M/z values of M0 were monitored for the 518 following intermediates: lactate $(\mathrm{m} / \mathrm{z} 261.2)$, fumarate $(\mathrm{m} / \mathrm{z} 287.1)$, succinate $(\mathrm{m} / \mathrm{z} 289.1)$, $519 \alpha$-ketoglutarate (m/z 360.2), malate (m/z 419.3), citrate (m/z 591.4), 2-HG (m/z 433.2) and 520 glutamate $(\mathrm{m} / \mathrm{z}$ 432.2). The mass isotopomer distribution of each compound was then 521 corrected for natural abundance using the respective standards.[34] We used an 522 appropriate set of linear simultaneous equations to calculate mole percent enrichment of 523 TCA cycle intermediates to understand glucose dependent or glucose independent 524 glutamine metabolism in myeloma cells.

525

526 Statistical Analysis

527 Fractional abundance of ${ }^{13} \mathrm{C}$ in the various TCA metabolites is expressed as mean \pm 528 standard error mean (SEM). Data were compared and analyzed using the paired t test, and 529 significance was defined as $\mathrm{p}<0.05$. For the quantitative levels of TCA cycle intermediates, 
530 given the non-normal distribution of the data, the differences between groups of interest 531 were compared and analyzed using the non-parametric Mann-Whitney U test, and 532 significance was defined as $\mathrm{p}<0.05$. This analysis was performed by using GraphPad Prism 533 version 7.00 for Windows, GraphPad Software, La Jolla California USA, www.graphpad.com. 534

535

536

537

538

539

540

541

542

543

544

545

546

547

548

549

550

551

552 


\section{FIGURE LEGENDS}

554 Figure 1A

555 Timeline of procedures/evaluations performed on the volunteers during the study day.

556 Figure 1B

557 Plasma glutamine enrichment during the $5-{ }^{13} \mathrm{C}$-glutamine infusion in each of the volunteers $558 \quad(\mathrm{~N}=7)$.

559 Figure 1C

560 Glutamine enrichment in paired bone marrow and peripheral blood plasma after 60 561 minutes of the $5-{ }^{13} \mathrm{C}$-glutamine infusion from each of the volunteers $(\mathrm{N}=7)$.

562 Figure 1D

563 Comparison of mean relative ${ }^{13} \mathrm{C}$ fractional enrichment of TCA cycle intermediates in 564 CD138 + and CD138 - cells from the bone marrows of volunteers $(\mathrm{N}=3)$. Error bars 565 represent SEM. n.s. is non-significant by paired t-test.

566 Figure 2A

567 Glutamine enrichment in bone marrow plasma after 60 minutes of the $\left[{ }^{13} \mathrm{C}_{5}\right]$-glutamine 568 infusion in patients with MGUS $(\mathrm{N}=11)$ and MM $(\mathrm{N}=12)$. Error bars represent SEM. n.s. is 569 non-significant by unpaired t-test.

$570 \quad$ Figure 2B

571 Comparison of mean relative ${ }^{13} \mathrm{C}$ fractional enrichment of TCA cycle intermediates in 572 CD138 + and CD138 - cells from the bone marrows of MGUS (N = 10) and MM (N = 11). 573 Error bars represent SEM. n.s. is non-significant, ${ }^{*} \mathrm{p}<0.05{ }^{*}{ }^{*} \mathrm{p}<0.01$ and ${ }^{* * *} \mathrm{p}<0.001$ 574 by paired t-test.

575 Figure 2C

576 Relative ${ }^{13} \mathrm{C}$ fractional enrichment (CD138 +/CD138-) of TCA cycle intermediates from each 577 MGUS $(\mathrm{N}=10)$ and $\mathrm{MM}(\mathrm{N}=11)$ patient.

578 Figure 3A

579 Hierarchical clustering analysis on the overall differential expression of genes between $580 \quad$ MGUS $(\mathrm{N}=6)$ and $\mathrm{MM}(\mathrm{N}=10)$ patients.

581 Figure 3B

582 Relative differences in mRNA expression of c-Myc, GLS, ASCT2 and SN2 between CD138 + 583 cells from MGUS $(\mathrm{N}=6)$ and MM $(\mathrm{N}=10)$ patients in context of their effect on glutamine 584 transport into the cell. 


\section{Figure 4A}

Violin plots comparing the median concentrations of different TCA metabolites in the bone marrow plasma between MGUS $(\mathrm{N}=11)$ and MM $(\mathrm{N}=12)$ groups. Data was analyzed by Mann-Whitney U test where ${ }^{* * *} \mathrm{p}<0.001,{ }^{* *} \mathrm{p}<0.01,{ }^{*} \mathrm{p}<0.05$, ${ }^{*} \mathrm{p}<0.1$ but $\geq 0.05$, n.s. non-significant.

\section{Figure 4B}

Violin plots comparing the median concentrations of different TCA metabolites in the peripheral blood plasma between MGUS $(\mathrm{N}=11)$ and MM $(\mathrm{N}=12)$ groups. Data was analyzed by Mann-Whitney U test where ${ }^{* * *} \mathrm{p}<0.001,{ }^{* *} \mathrm{p}<0.01,{ }^{*} \mathrm{p}<0.05$, ${ }^{*} \mathrm{p}<0.1$ but $\geq 0.05$, n.s. non-significant.

\section{Figure 4C}

Violin plots comparing the median concentrations of aspartate and glutamate in the bone marrow plasma between the volunteers ( $N=7)$, MGUS $(N=11)$ and MM $(N=12)$ groups. Data was analyzed by Mann-Whitney U test where ${ }^{* * *} \mathrm{p}<0.001,{ }^{* *} \mathrm{p}<0.01,{ }^{*} \mathrm{p}<0.05$, ${ }^{*} \mathrm{p}$ $<0.1$ but $\geq 0.05$, n.s. non-significant.

\section{Figure 4D}

$\mathrm{XY}$-correlation plots comparing the concentrations of aspartate and glutamate in the bone marrow plasma of patients with MGUS and MM and the percentage of clonal plasma cells in their bone marrow.

\section{Figure 5A}

Immunohistochemical staining of the bone marrow for CD138 + clonal plasma cells in MM patient \#2 with primary plasma cell leukemia as well as peripheral smear evaluation demonstrating the presence of circulating plasma cells.

\section{Figure 5B}

Positron Emission Tomography - Computed Tomography $(\boldsymbol{P E T} / \boldsymbol{C T})$ demonstrating the presence of a large plasmacytoma in the right chest wall as well as immunohistochemical staining of the bone marrow for CD138 + clonal plasma cells in MM patient \#7 with no marrow involvement.

\section{Figure 5C}

Graphical visualization of the concentrations of the TCA cycle intermediate such as glutamate, succinate, fumarate, malate and aspartate in the bone marrow plasma of MM patient \#2 with primary plasma cell leukemia and MM patient \#7 with respect to that of the remainder of the MM patients (represented by the mean ----, maximum and minimum ...... values). 
620 LIST OF ABBREVIATION

621 MGUS: Monoclonal Gammopathy Of Undetermined Significance

622 MM: Multiple Myeloma

623 SMM: Smoldering multiple myeloma

624 TCA: Tricarboxylic acid

625 cPCs: Clonal plasma cells

626 GLS: Glutaminase

627 SIRM: Stable isotope resolved metabolomics

628 HMCL: Human myeloma cell line

629

630

631

632

633

634

635

636

637

638

639

640

641

642 


\section{DECLARATIONS}

644

645 Ethics approval and consent to participate

646 Approval for this study (IRB\#: 17-00313) was obtained from the Mayo Clinic Institutional

647 Review Board in accordance with the federal regulations and the principles of the

648 Declaration of Helsinki.

649

650 Consent for publication

651 This is not applicable. There are no personal identifiers utilized in this manuscript and for

652 MM \#2 and MM \#7 whose bone marrow and radiographical images are provided are

653 deceased.

654

655 Availability of data and materials

656 The datasets used and/or analyzed during the current study are available from the

657 corresponding author on reasonable request.

658

659 Competing interests

660 There are no competing interests or conflicts of interest among any of the authors.

661

$662 \quad$ Funding

663 Research reported in this publication was supported by the National Cancer Institute of the

664 National Institutes of Health under Award Number K23CA218742. The content is solely the 665 responsibility of the authors and does not necessarily represent the official views of the 
666 National Institutes of Health. This research is also supported in part by the CTSA Grant UL1

667 TR000135 from the National Center for Advancing Translational Sciences (NCATS), a

668 component of the National Institutes of Health (NIH), Fraternal Order of the Eagles Grant of

669 the Mayo Clinic Cancer Center, Predolin Foundation for Hematological Malignancies and

670 the Marion Schwartz Foundation for Multiple Myeloma. Finally, this publication was also

671 made possible by Mayo Clinic Metabolomics Resource Core through grant number

672 U24DK100469 from the National Institute of Diabetes and Digestive and Kidney Diseases

673 and originates from the National Institutes of Health Director's Common Fund.

674

675 Authors' contributions

676 W.I.G and K.S.N. designed the study, analyzed the data and wrote the manuscript; J.J.

677 performed the bioinformatics analysis and reviewed the manuscript; D.J. performed the

678 histological analyses in this study and reviewed the manuscript; X. M. P., J.G. and A.B.

679 contributed in performing and coordinating the metabolomics assessments; E.A. and L.E.

680 assisted in data analysis and reviewed the manuscript. T.H. and S.K.K was involved in

681 analyzing the data and reviewing the manuscript.

682

683 Acknowledgements

684 We appreciate the combined help of the Department of Anesthesiology, Mayo Clinic (Dr.

685 Todd Kor MD and Jodi Cerar RN), the bone marrow biopsy procedural team (Jennifer J.

686 Larson RN, Richard J. Allen RN, Joseph J. Haack RN, David E. Ruffridge RN, Amie L. Turner RN,

687 Colleen Byrnes RN) and the Clinical and Trials Unit, Mayo Clinic (Lisa K. Haffey RN) who all

688 helped in the procedures involved in conducting this study. 


\section{REFERENCES}

690 1. Siegel RL, Miller KD, Jemal A: Cancer statistics, 2016. CA Cancer J Clin 2016, 66:7-30.

691 2. Kyle RA, Gertz MA, Witzig TE, Lust JA, Lacy MQ, Dispenzieri A, Fonseca R, Rajkumar SV, Offord

692 JR, Larson DR, et al: Review of 1027 patients with newly diagnosed multiple myeloma. Mayo

$693 \quad$ Clin Proc 2003, 78:21-33.

694 3. Kumar SK, Rajkumar SV, Dispenzieri A, Lacy MQ, Hayman SR, Buadi FK, Zeldenrust SR, Dingli D,

695 Russell SJ, Lust JA, et al: Improved survival in multiple myeloma and the impact of novel

696 therapies. Blood 2008, 111:2516-2520.

697 4. Gonsalves WI, Rajkumar SV, Go RS, Dispenzieri A, Gupta V, Singh PP, Buadi FK, Lacy MQ, Kapoor

698 P, Dingli D, et al: Trends in survival of patients with primary plasma cell leukemia: a

699 population-based analysis. Blood 2014, 124:907-912.

700 5. Brenner H, Gondos A, Pulte D: Recent major improvement in long-term survival of younger

701 patients with multiple myeloma. Blood 2008, 111:2521-2526.

702 6. Kumar SK, Dispenzieri A, Lacy MQ, Gertz MA, Buadi FK, Pandey S, Kapoor P, Dingli D, Hayman SR, 703 Leung $\mathrm{N}$, et al: Continued improvement in survival in multiple myeloma: changes in early mortality and outcomes in older patients. Leukemia 2014, 28:1122-1128.

705 7. Ward PS, Thompson CB: Metabolic reprogramming: a cancer hallmark even warburg did not 706 anticipate. Cancer Cell 2012, 21:297-308.

707 8. Vander Heiden MG, Cantley LC, Thompson CB: Understanding the Warburg effect: the metabolic requirements of cell proliferation. Science 2009, 324:1029-1033.

9. Dang CV: Rethinking the Warburg effect with Myc micromanaging glutamine metabolism. Cancer Res 2010, 70:859-862. 
711 10. Terunuma A, Putluri N, Mishra P, Mathe EA, Dorsey TH, Yi M, Wallace TA, Issaq HJ, Zhou M,

712 Killian JK, et al: MYC-driven accumulation of 2-hydroxyglutarate is associated with breast

$713 \quad$ cancer prognosis. J Clin Invest 2014, 124:398-412.

714 11. Le A, Lane AN, Hamaker M, Bose S, Gouw A, Barbi J, Tsukamoto T, Rojas CJ, Slusher BS, Zhang H, et al: Glucose-independent glutamine metabolism via TCA cycling for proliferation and survival in B cells. Cell Metab 2012, 15:110-121.

717 12. Chng WJ, Huang GF, Chung TH, Ng SB, Gonzalez-Paz N, Troska-Price T, Mulligan G, Chesi M, Bergsagel PL, Fonseca R: Clinical and biological implications of MYC activation: a common difference between MGUS and newly diagnosed multiple myeloma. Leukemia 2011, 25:1026-

720 1035.

721 13. Chesi M, Robbiani DF, Sebag M, Chng WJ, Affer M, Tiedemann R, Valdez R, Palmer SE, Haas SS, Stewart AK, et al: AID-dependent activation of a MYC transgene induces multiple myeloma in a conditional mouse model of post-germinal center malignancies. Cancer Cell 2008, 13:167-180.

724 14. van Geldermalsen M, Wang Q, Nagarajah R, Marshall AD, Thoeng A, Gao D, Ritchie W, Feng Y, Bailey CG, Deng N, et al: ASCT2/SLC1A5 controls glutamine uptake and tumour growth in triple-negative basal-like breast cancer. Oncogene 2016, 35:3201-3208.

727 15. Gao P, Tchernyshyov I, Chang TC, Lee YS, Kita K, Ochi T, Zeller KI, De Marzo AM, Van Eyk JE, Mendell JT, Dang CV: c-Myc suppression of miR-23a/b enhances mitochondrial glutaminase expression and glutamine metabolism. Nature 2009, 458:762-765.

16. Pavlova NN, Thompson CB: The Emerging Hallmarks of Cancer Metabolism. Cell Metab 2016, 23:27-47.

17. Cantor JR, Abu-Remaileh M, Kanarek N, Freinkman E, Gao X, Louissaint A, Jr., Lewis CA, Sabatini DM: Physiologic Medium Rewires Cellular Metabolism and Reveals Uric Acid as an Endogenous Inhibitor of UMP Synthase. Cell 2017, 169:258-272 e217. 
18. Gonsalves WI, Ramakrishnan V, Hitosugi T, Ghosh T, Jevremovic D, Dutta T, Sakrikar D, Petterson XM, Wellik L, Kumar SK, Nair KS: Glutamine-derived 2-hydroxyglutarate is associated with disease progression in plasma cell malignancies. JCI Insight 2018, 3.

19. Muir A, Danai LV, Gui DY, Waingarten CY, Lewis CA, Vander Heiden MG: Environmental cystine drives glutamine anaplerosis and sensitizes cancer cells to glutaminase inhibition. Elife 2017, 6.

20. Kyle RA, Durie BG, Rajkumar SV, Landgren O, Blade J, Merlini G, Kroger N, Einsele H, Vesole DH, Dimopoulos M, et al: Monoclonal gammopathy of undetermined significance (MGUS) and smoldering (asymptomatic) multiple myeloma: IMWG consensus perspectives risk factors for progression and guidelines for monitoring and management. Leukemia 2010, 24:1121-1127.

21. Kyle RA, Remstein ED, Therneau TM, Dispenzieri A, Kurtin PJ, Hodnefield JM, Larson DR, Plevak MF, Jelinek DF, Fonseca R, et al: Clinical course and prognosis of smoldering (asymptomatic) multiple myeloma. N Engl J Med 2007, 356:2582-2590.

22. Dispenzieri A, Stewart AK, Chanan-Khan A, Rajkumar SV, Kyle RA, Fonseca R, Kapoor P, Bergsagel PL, McCurdy A, Gertz MA, et al: Smoldering multiple myeloma requiring treatment: time for a new definition? Blood 2013, 122:4172-4181.

23. Mateos MV, Hernandez MT, Giraldo P, de la Rubia J, de Arriba F, Lopez Corral L, Rosinol L, Paiva B, Palomera L, Bargay J, et al: Lenalidomide plus dexamethasone for high-risk smoldering multiple myeloma. N Engl J Med 2013, 369:438-447.

24. Bolzoni M, Chiu M, Accardi F, Vescovini R, Airoldi I, Storti P, Todoerti K, Agnelli L, Missale G, Andreoli R, et al: Dependence on glutamine uptake and glutamine addiction characterize myeloma cells: a new attractive target. Blood 2016, 128:667-679.

25. Lam WY, Jash A, Yao CH, D'Souza L, Wong R, Nunley RM, Meares GP, Patti GJ, Bhattacharya D: Metabolic and Transcriptional Modules Independently Diversify Plasma Cell Lifespan and Function. Cell Rep 2018, 24:2479-2492 e2476. 
759 26. Faubert B, Li KY, Cai L, Hensley CT, Kim J, Zacharias LG, Yang C, Do QN, Doucette S, Burguete D, 760 et al: Lactate Metabolism in Human Lung Tumors. Cell 2017, 171:358-371 e359.

761 27. Hensley CT, Faubert B, Yuan Q, Lev-Cohain N, Jin E, Kim J, Jiang L, Ko B, Skelton R, Loudat L, et al: Metabolic Heterogeneity in Human Lung Tumors. Cell 2016, 164:681-694.

28. Sellers K, Fox MP, Bousamra M, 2nd, Slone SP, Higashi RM, Miller DM, Wang Y, Yan J, Yuneva MO, Deshpande R, et al: Pyruvate carboxylase is critical for non-small-cell lung cancer proliferation. J Clin Invest 2015, 125:687-698.

29. Fan TW, Lane AN, Higashi RM, Farag MA, Gao H, Bousamra M, Miller DM: Altered regulation of metabolic pathways in human lung cancer discerned by (13)C stable isotope-resolved metabolomics (SIRM). Mol Cancer 2009, 8:41.

30. Courtney KD, Bezwada D, Mashimo T, Pichumani K, Vemireddy V, Funk AM, Wimberly J, McNeil SS, Kapur P, Lotan Y, et al: Isotope Tracing of Human Clear Cell Renal Cell Carcinomas Demonstrates Suppressed Glucose Oxidation In Vivo. Cell Metab 2018, 28:793-800 e792.

31. Maher EA, Marin-Valencia I, Bachoo RM, Mashimo T, Raisanen J, Hatanpaa KJ, Jindal A, Jeffrey FM, Choi C, Madden C, et al: Metabolism of [U-13 C]glucose in human brain tumors in vivo. NMR Biomed 2012, 25:1234-1244.

32. Xing Y, Yu T, Wu YN, Roy M, Kim J, Lee C: An expectation-maximization algorithm for

33. Love MI, Huber W, Anders S: Moderated estimation of fold change and dispersion for RNA-seq data with DESeq2. Genome Biol 2014, 15:550.

34. Jennings ME, 2nd, Matthews DE: Determination of complex isotopomer patterns in isotopically 781 labeled compounds by mass spectrometry. Anal Chem 2005, 77:6435-6444. 
783 Table 1: Characteristics of the volunteers participating and the dosages of $5-13 \mathrm{C}$-glutamine 784 infused and their pre- and post-blood plasma urea nitrogen (BUN) and ammonia levels.
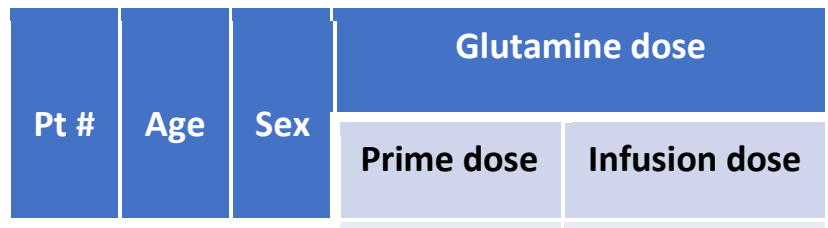

\section{$\operatorname{BUN}(\mathrm{mg} / \mathrm{dL}) \quad \mathrm{NH}_{3}(\mu \mathrm{mol} / \mathrm{L})$}

\begin{tabular}{|c|c|c|c|c|}
\hline Prime dose & Infusion dose & Pre & Post & Pre \\
\hline
\end{tabular}

\begin{tabular}{|l|l|l|l|l|l|l|l|l|}
1 & 35 & $\mathrm{~F}$ & $3 \mathrm{mg} / \mathrm{kg}$ & $3 \mathrm{mg} / \mathrm{kg}$ & 15 & 14 & $<10$ & 15
\end{tabular}

\begin{tabular}{l|l|l|l|l|l|l|l|l|}
\hline 2 & 24 & $\mathrm{M}$ & $3 \mathrm{mg} / \mathrm{kg}$ & $3 \mathrm{mg} / \mathrm{kg}$ & 20 & 15 & $12<10$ \\
\hline
\end{tabular}

\begin{tabular}{|l|l|l|l|l|l|l|l|l|}
\hline 3 & 27 & $\mathrm{~F}$ & $3 \mathrm{mg} / \mathrm{kg}$ & $3 \mathrm{mg} / \mathrm{kg}$ & 16 & 16 & $<10$ & $<10$ \\
\hline
\end{tabular}

\begin{tabular}{|l|l|l|l|l|l|l|l|l|}
\hline 4 & 29 & $\mathrm{M}$ & $3 \mathrm{mg} / \mathrm{kg}$ & $3 \mathrm{mg} / \mathrm{kg}$ & 12 & 12 & 15 & 18 \\
\hline 5 & 24 & $\mathrm{M}$ & $3.5 \mathrm{mg} / \mathrm{kg}$ & $3.5 \mathrm{mg} / \mathrm{kg}$ & 16 & 15 & $<10$ & $<10$ \\
\hline
\end{tabular}

\begin{tabular}{|l|l|l|l|l|l|l|l|l|}
\hline 6 & 29 & $\mathrm{~F}$ & $4 \mathrm{mg} / \mathrm{kg}$ & $4 \mathrm{mg} / \mathrm{kg}$ & 19 & 13 & $<10$ & 24 \\
\hline 7 & 52 & $\mathrm{~F}$ & $4 \mathrm{mg} / \mathrm{kg}$ & $4 \mathrm{mg} / \mathrm{kg}$ & 9 & 13 & $<10$ & 19 \\
\hline
\end{tabular}

798

799

800

801

802

803

804

805

806

807

808

809

810

811 
812 Table 2: Clinical characteristics of the MGUS patients and their corresponding bolus and 813 continuous infusion dosages of $\left[{ }^{13} \mathrm{C}_{5}\right]$-glutamine.

814

\begin{tabular}{|c|c|c|c|c|c|}
\hline Patient \# & Age & Sex & M-Spike & Isotype & Glutamine enrichment \\
\hline MGUS \#1 & 52 & $\mathrm{~F}$ & $0.4 \mathrm{~g} / \mathrm{dL}$ & IgG Lambda & $5.21 \%$ \\
\hline MGUS \#2 & 65 & M & $\begin{array}{c}\mathrm{NQ} \\
\operatorname{IgA}: 476 \mathrm{mg} / \mathrm{dL}\end{array}$ & IgA Карра & $4.78 \%$ \\
\hline MGUS \#3 & 71 & M & $1.2 \mathrm{~g} / \mathrm{dL}$ & IgG Lambda & $4.61 \%$ \\
\hline MGUS \#4 & 66 & M & $0.7 \mathrm{~g} / \mathrm{dL}$ & IgG Карра & $5.57 \%$ \\
\hline MGUS \#5 & 69 & $M$ & $1.4 \mathrm{~g} / \mathrm{dL}$ & IgG Lambda & $3.49 \%$ \\
\hline MGUS \#6 & 48 & M & $1.2 \mathrm{~g} / \mathrm{dL}$ & IgG Карра & $4.90 \%$ \\
\hline MGUS \#7 & 56 & $\mathrm{~F}$ & $1.2 \mathrm{~g} / \mathrm{dL}$ & IgG Карра & $5.84 \%$ \\
\hline MGUS \#8 & 61 & $\mathrm{~F}$ & $\begin{array}{c}\mathrm{NQ} \\
\text { IgG: } 867 \mathrm{mg} / \mathrm{dL}\end{array}$ & IgG Lambda & $6.31 \%$ \\
\hline MGUS \#9 & 71 & $M$ & $\begin{array}{c}\mathrm{NQ} \\
\text { Kappa FLC: } 47.5 \mathrm{mg} / \mathrm{dL}\end{array}$ & Free Kappa & $6.25 \%$ \\
\hline MGUS \#10 & 67 & $\mathrm{~F}$ & $0.6 \mathrm{~g} / \mathrm{dL}$ & IgG Карра & $5.56 \%$ \\
\hline MGUS \#11 & 56 & $\mathrm{~F}$ & $\begin{array}{c}\mathrm{NQ} \\
\operatorname{IgA}: 464 \mathrm{mg} / \mathrm{dL}\end{array}$ & IgA Карра & $6.00 \%$ \\
\hline
\end{tabular}

816 NQ: Non-Quantifiable 
821 Table 3: Clinical characteristics of the MM patients and their corresponding bolus and

822 continuous infusion dosages of $\left[{ }^{13} \mathrm{C}_{5}\right]$-glutamine.

\begin{tabular}{|c|c|c|c|c|c|c|c|c|c|}
\hline Patient \# & Age & Sex & M-Spike & Isotype & $\begin{array}{l}\text { Glutamine } \\
\text { enrichment }\end{array}$ & $\begin{array}{c}\text { Primary } \\
\text { Cytogenetics }\end{array}$ & $\begin{array}{c}\text { Prior Lines } \\
\text { of } \\
\text { Therapy }\end{array}$ & BMPC\% & S-Phase $\%$ \\
\hline MM \#1 & 72 & $\mathrm{~F}$ & $1.3 \mathrm{~g} / \mathrm{dL}$ & IgG Kappa & $4.25 \%$ & Trisomies & 2 & $20 \%$ & $1.6 \%$ \\
\hline MM \#2 & 65 & $\mathrm{~F}$ & $\mathrm{NQ}$ & NS & $2.89 \%$ & $t(11 ; 14),+1 q$ & 4 & $95 \%$ & $23.8 \%$ \\
\hline MM \#3 & 71 & $M$ & $1.5 \mathrm{~g} / \mathrm{dL}$ & IgG Kappa & $5.40 \%$ & Trisomies & 3 & $15 \%$ & $0.7 \%$ \\
\hline MM \#4 & 71 & M & $0.5 \mathrm{~g} / \mathrm{dL}$ & IgG Kappa & $5.49 \%$ & Trisomies, $+1 q$ & 1 & $40 \%$ & $2.6 \%$ \\
\hline MM \#5 & 76 & $\mathrm{~F}$ & $\begin{array}{c}\text { NQ } \\
\text { Kappa } \\
\text { FLC: } 47.6 \\
\text { mg/dL }\end{array}$ & $\begin{array}{l}\text { Free } \\
\text { Kappa }\end{array}$ & $6.61 \%$ & $\begin{array}{c}\text { Myc sep, }+1 q,- \\
17 p\end{array}$ & 2 & $15 \%$ & $3.0 \%$ \\
\hline MM \#6 & 58 & $\mathrm{~F}$ & $\begin{array}{c}\mathrm{NQ} \\
\text { Lambda } \\
\text { FLC: } 11 \\
\mathrm{mg} / \mathrm{dL}\end{array}$ & $\begin{array}{c}\text { Free } \\
\text { Lambda }\end{array}$ & $6.80 \%$ & IgH sep, $-17 p$ & 3 & $100 \%$ & $8.2 \%$ \\
\hline MM \#7 & 53 & M & $1.9 \mathrm{~g} / \mathrm{dL}$ & IgG Kappa & $3.35 \%$ & N/A & 5 & $0 \%$ & N/A \\
\hline MM \#8 & 69 & $\mathrm{~F}$ & $\begin{array}{c}\mathrm{NQ} \\
\text { Lambda } \\
\text { FLC: } 51 \\
\mathrm{mg} / \mathrm{dL}\end{array}$ & $\begin{array}{c}\text { Free } \\
\text { Lambda }\end{array}$ & $6.63 \%$ & Trisomies, $+1 q$ & 1 & $20 \%$ & $4.5 \%$ \\
\hline MM \#9 & 75 & M & $\begin{array}{c}\text { Lambda } \\
\text { FLC: } 40.5 \\
\text { mg/dL }\end{array}$ & $\begin{array}{l}\text { Free } \\
\text { Lambda }\end{array}$ & $6.45 \%$ & Trisomies & 4 & $20 \%$ & $2.0 \%$ \\
\hline MM \#10 & 71 & M & $1.9 \mathrm{~g} / \mathrm{dL}$ & IgA Карра & $6.27 \%$ & $\begin{array}{c}t(11 ; 14),+1 q,- \\
17 p\end{array}$ & 3 & $50 \%$ & $1.3 \%$ \\
\hline MM \#11 & 71 & M & NQ & NS & $5.99 \%$ & $t(11 ; 14),-17 p$ & 2 & $1 \%$ & N/A \\
\hline MM \#12 & 61 & $M$ & $1.2 \mathrm{~g} / \mathrm{dL}$ & IgG Kappa & $4.35 \%$ & Trisomies & 1 & $5 \%$ & $1.0 \%$ \\
\hline
\end{tabular}

824 NQ: Non-Quantifiable; NS: non-secretory; BMPC\%: bone marrow plasma cell percentage 


\section{Start $5-{ }^{13} \mathrm{C}$-Glutamine}

bolus followed by infusion

$\mathrm{T}=\mathbf{0}$

Stop glutamine infusion

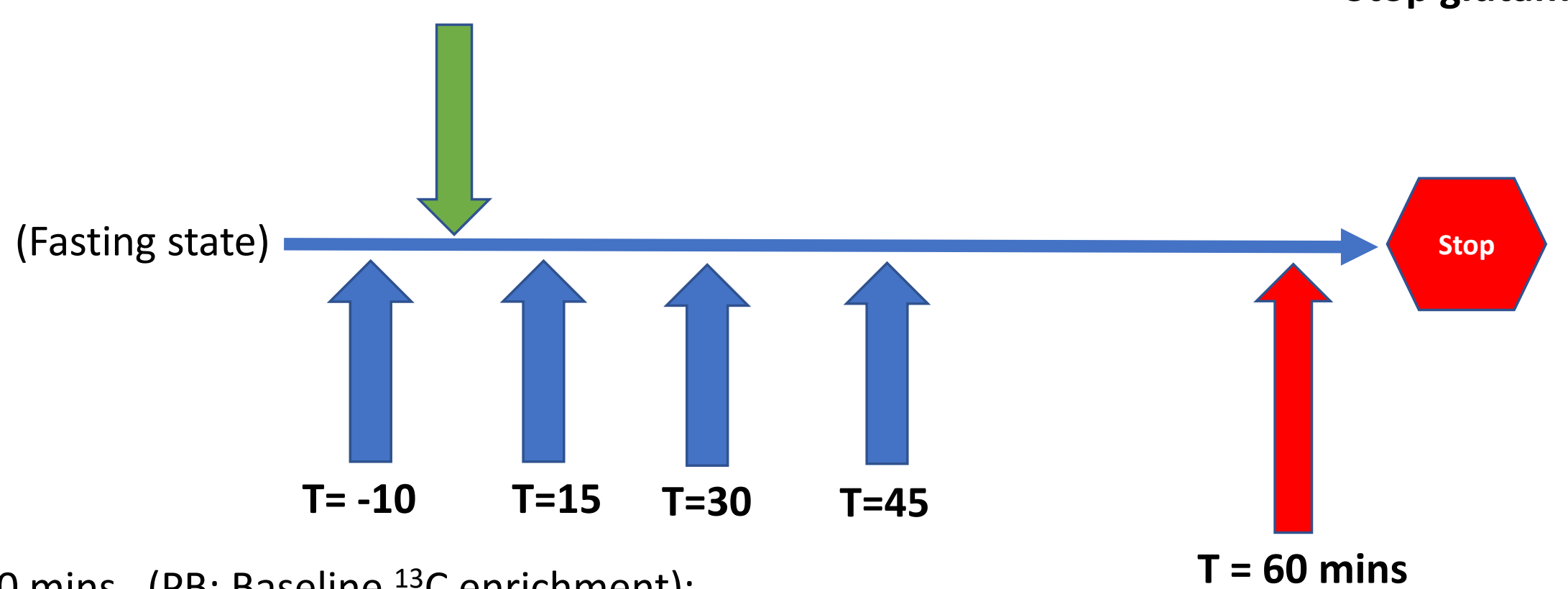

$\mathrm{T}=-10$ mins (PB: Baseline ${ }^{13} \mathrm{C}$ enrichment);

$\mathbf{T}=\mathbf{6 0}$ mins

$\mathrm{T}=15,30,45$ and 60 mins (PB: Subsequent ${ }^{13} \mathrm{C}$ enrichment)

(Bone marrow aspiration)

Figure 1A: Timeline of procedures/evaluations performed on the volunteers during the study day. PB: peripheral blood assessment 


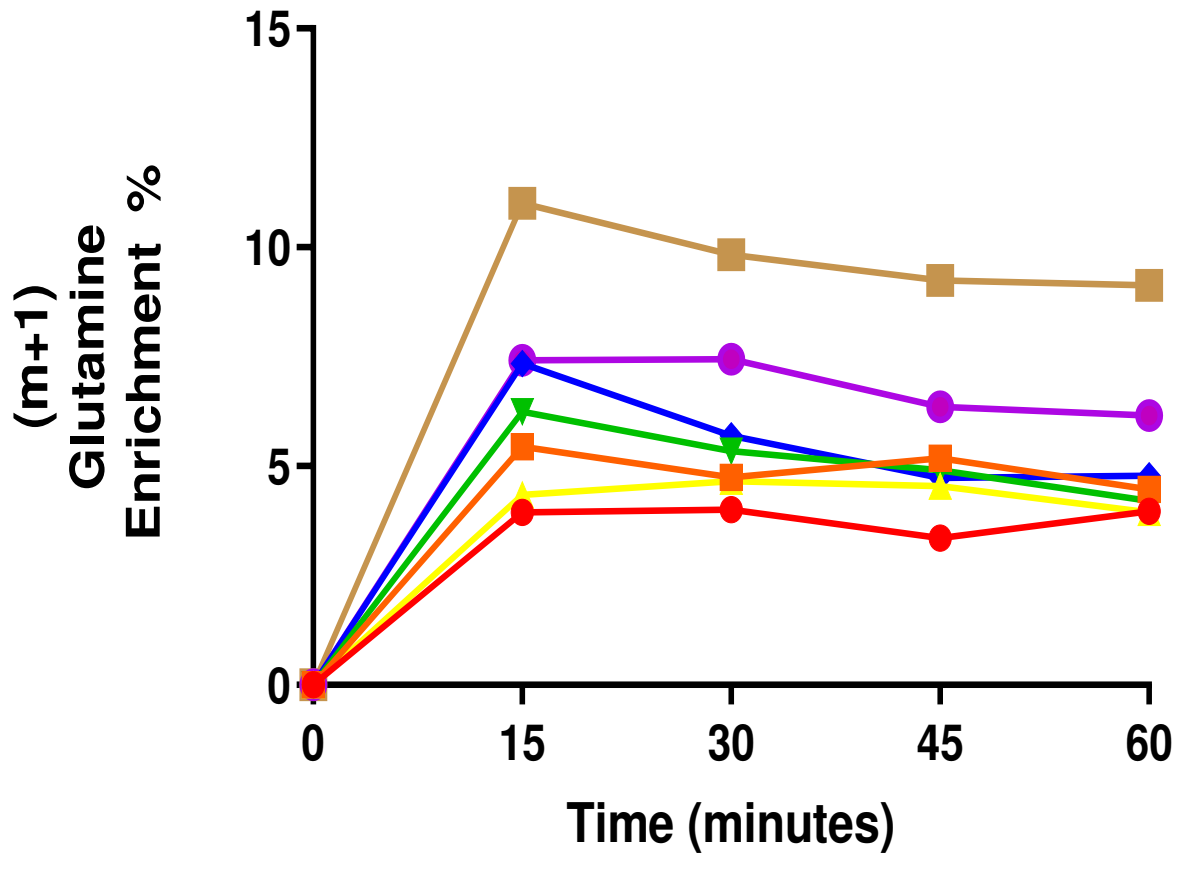

$\rightarrow \operatorname{Pt} \# 1(3 \mathrm{mg} / \mathrm{kg})$

$\rightarrow-\operatorname{Pt} \# 2(3 \mathrm{mg} / \mathrm{kg})$

- Pt \#3 (3 mg/kg)

$\rightarrow \mathrm{Pt} \# 4(3 \mathrm{mg} / \mathrm{kg})$

$\rightarrow \operatorname{Pt} \# 5(3.5 \mathrm{mg} / \mathrm{kg})$

$\rightarrow \operatorname{Pt} \# 6(4 \mathrm{mg} / \mathrm{kg})$

- Pt \#7 (4 mg/kg)

Figure 1B: Plasma glutamine enrichment during the $5-{ }^{13} \mathrm{C}$-glutamine infusion in each of the volunteers $(\mathrm{N}=7)$. 


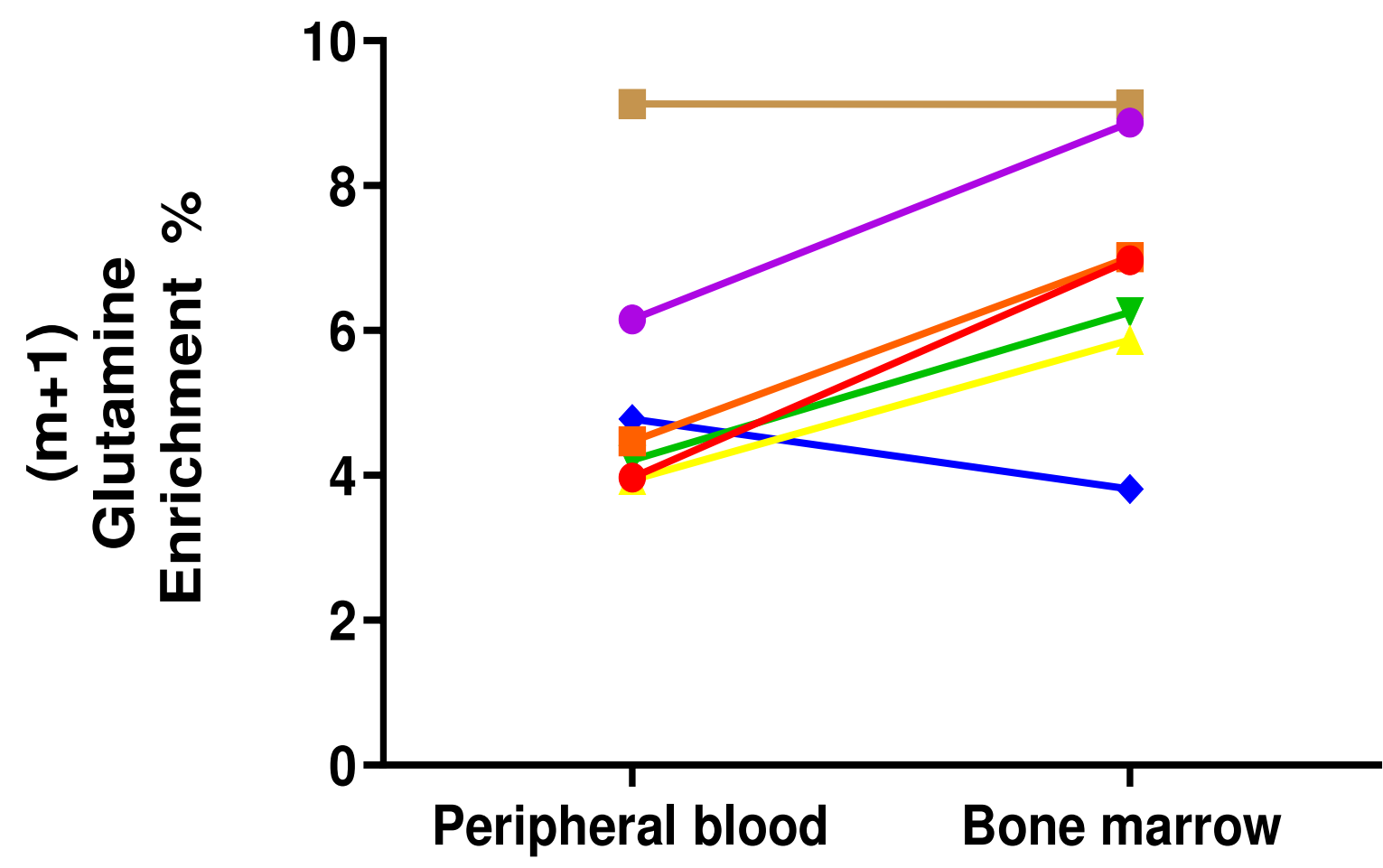

$\rightarrow \operatorname{Pt} \# 1$

$\rightarrow-\operatorname{Pt} \# 2$

Pt \#3

$\rightarrow \mathrm{Pt} \# 4$

$\rightarrow \operatorname{Pt} \# 5$

$\rightarrow \operatorname{Pt} \# 6$

$\rightarrow-\operatorname{Pt} \# 7$

Figure 1C: Glutamine enrichment in paired bone marrow and peripheral blood plasma after 60 minutes of the $5-{ }^{13} \mathrm{C}$ glutamine infusion from each of the volunteers $(\mathrm{N}=7)$. 


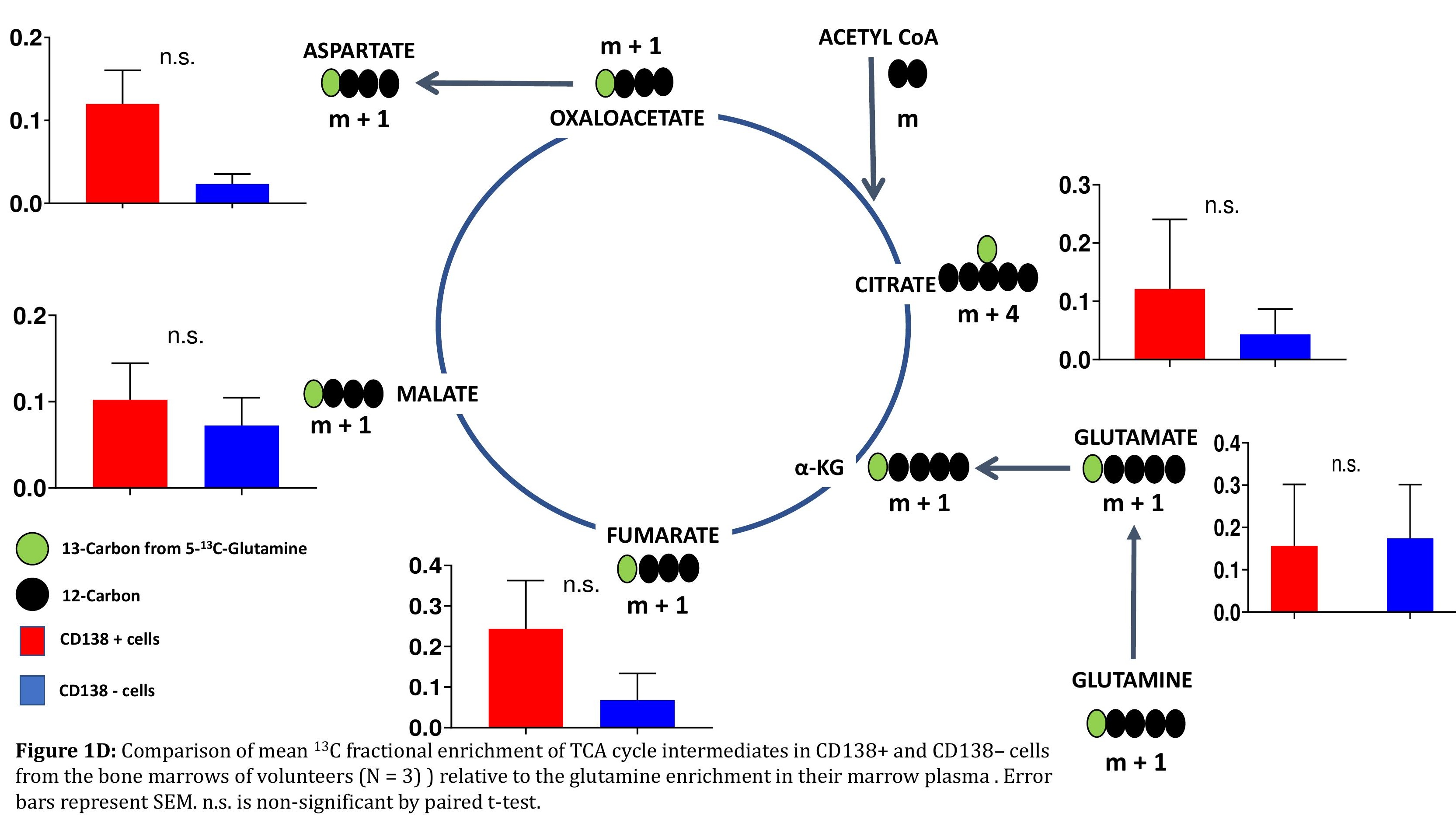




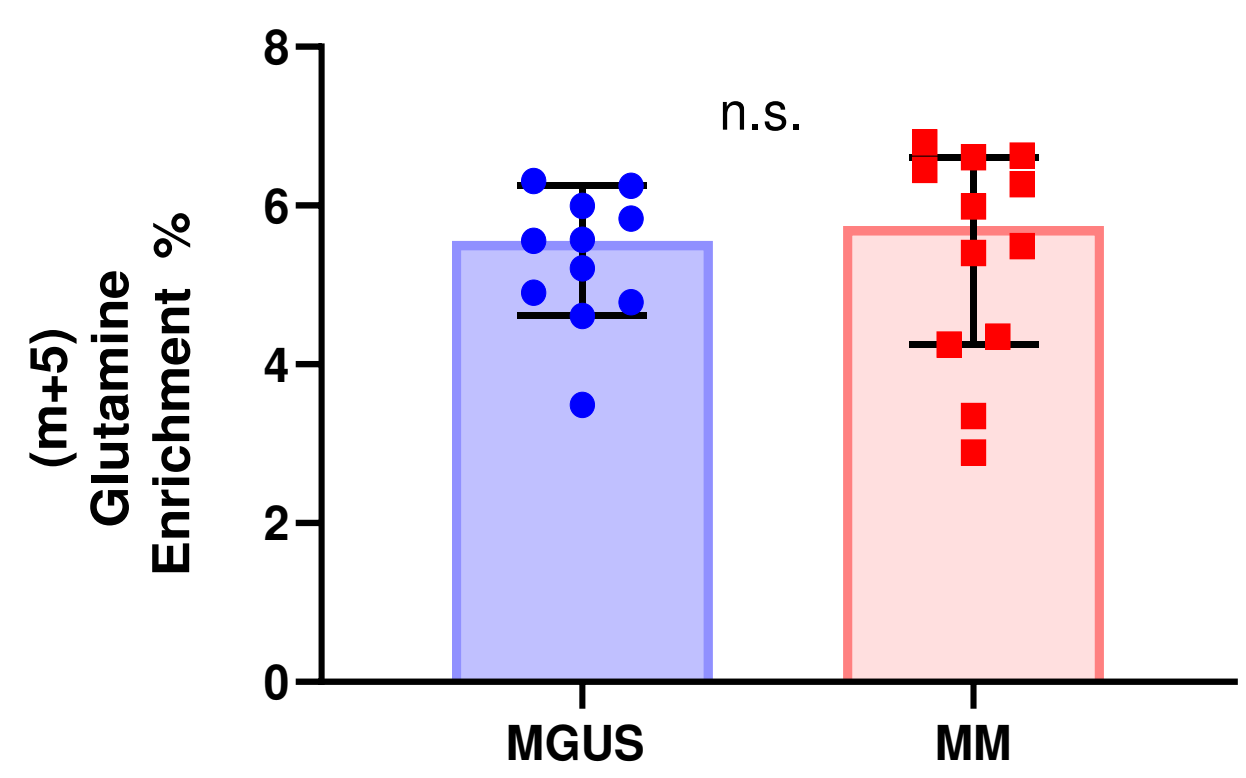

Figure 2A: Glutamine enrichment in bone marrow plasma after 60 minutes of the $\left[{ }^{13} \mathrm{C}_{5}\right]$-glutamine infusion in patients with $\mathrm{MGUS}(\mathrm{N}=11)$ and MM $(\mathrm{N}=12)$. Error bars represent SEM. n.s. is non-significant by unpaired t-test. 

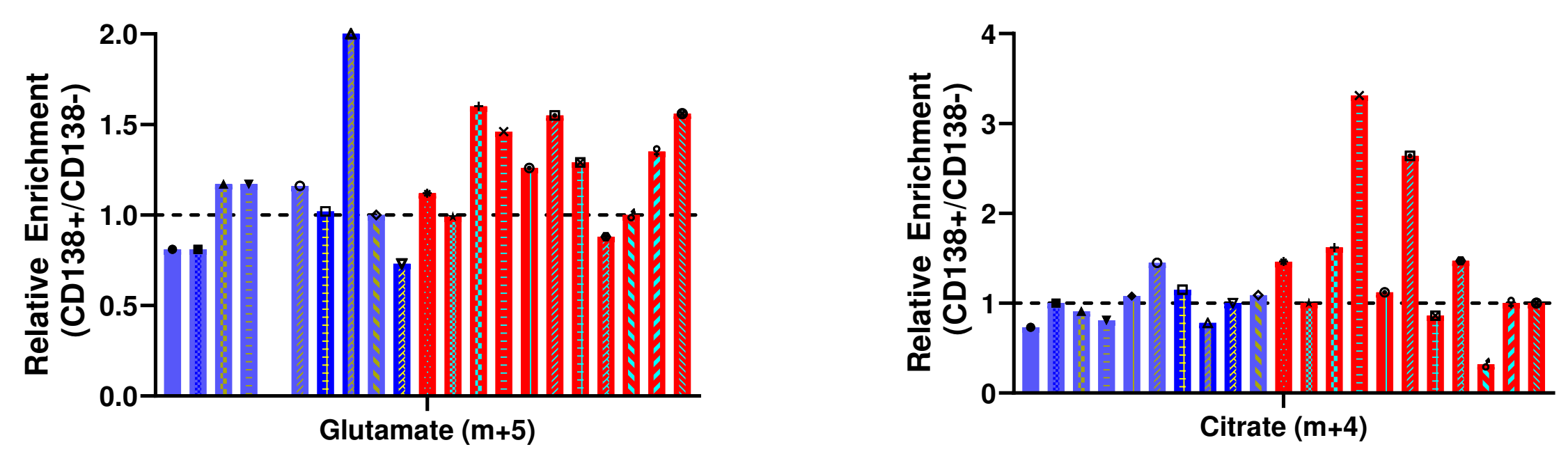

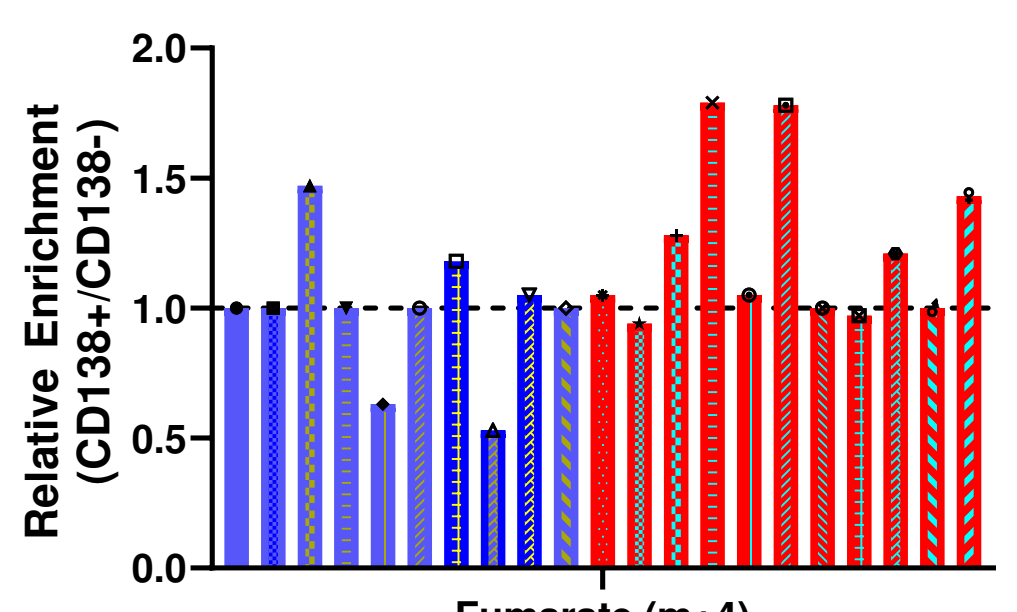

Fumarate $(m+4)$

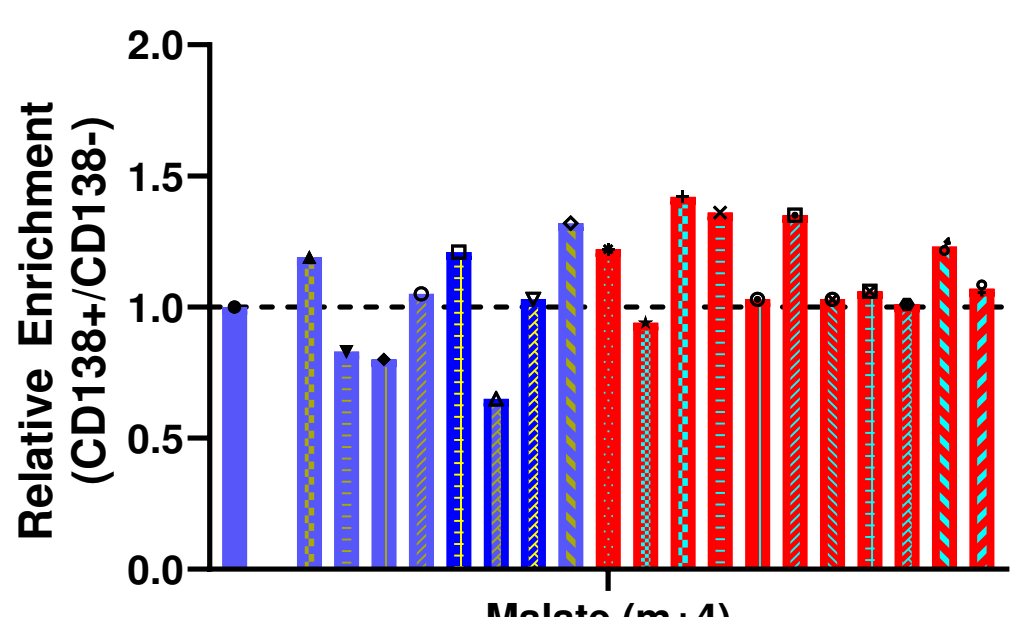

Malate $(m+4)$

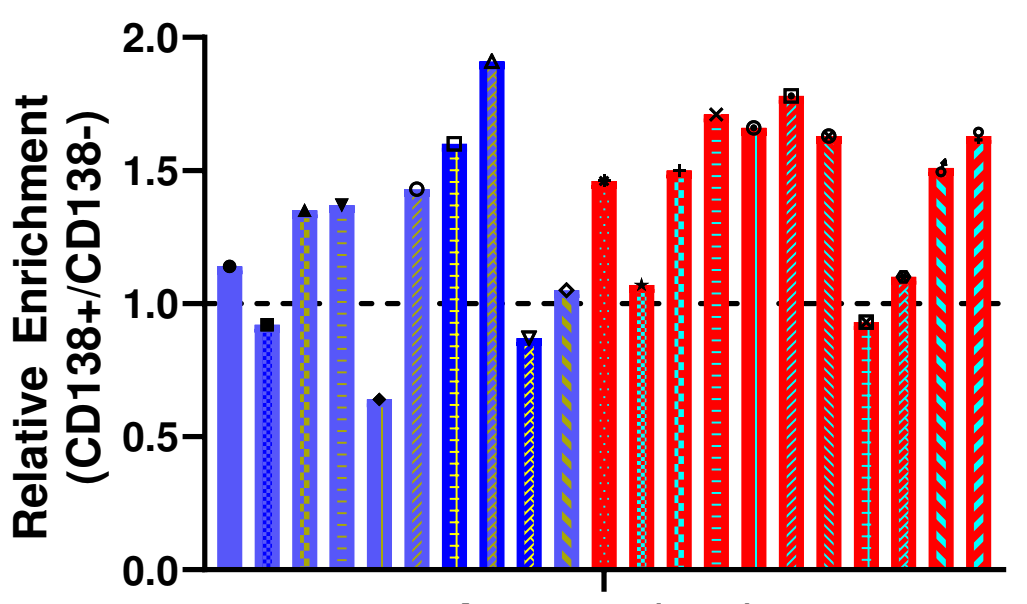

Aspartate $(m+4)$

Individual MM patients

Individual MGUS patients

Figure 2C: ${ }^{13} \mathrm{C}$ fractional enrichment of intermediate upon the first turn of the TCA cycle (CD138+/CD138-) from each MGUS (N = 10) and MM (N = 11) patient. MGUS\#5 and MGUS\#2 were unable to have their glutamate $(m+5)$ and malate $(m+2)$ assessed due to technical errors during GC-MS assessment and have been not reported. 
Figure 3A: Hierarchical clustering analysis on the overall differential expression of genes between MGUS $(\mathrm{N}=6)$ and MM $(\mathrm{N}=10)$ patients.

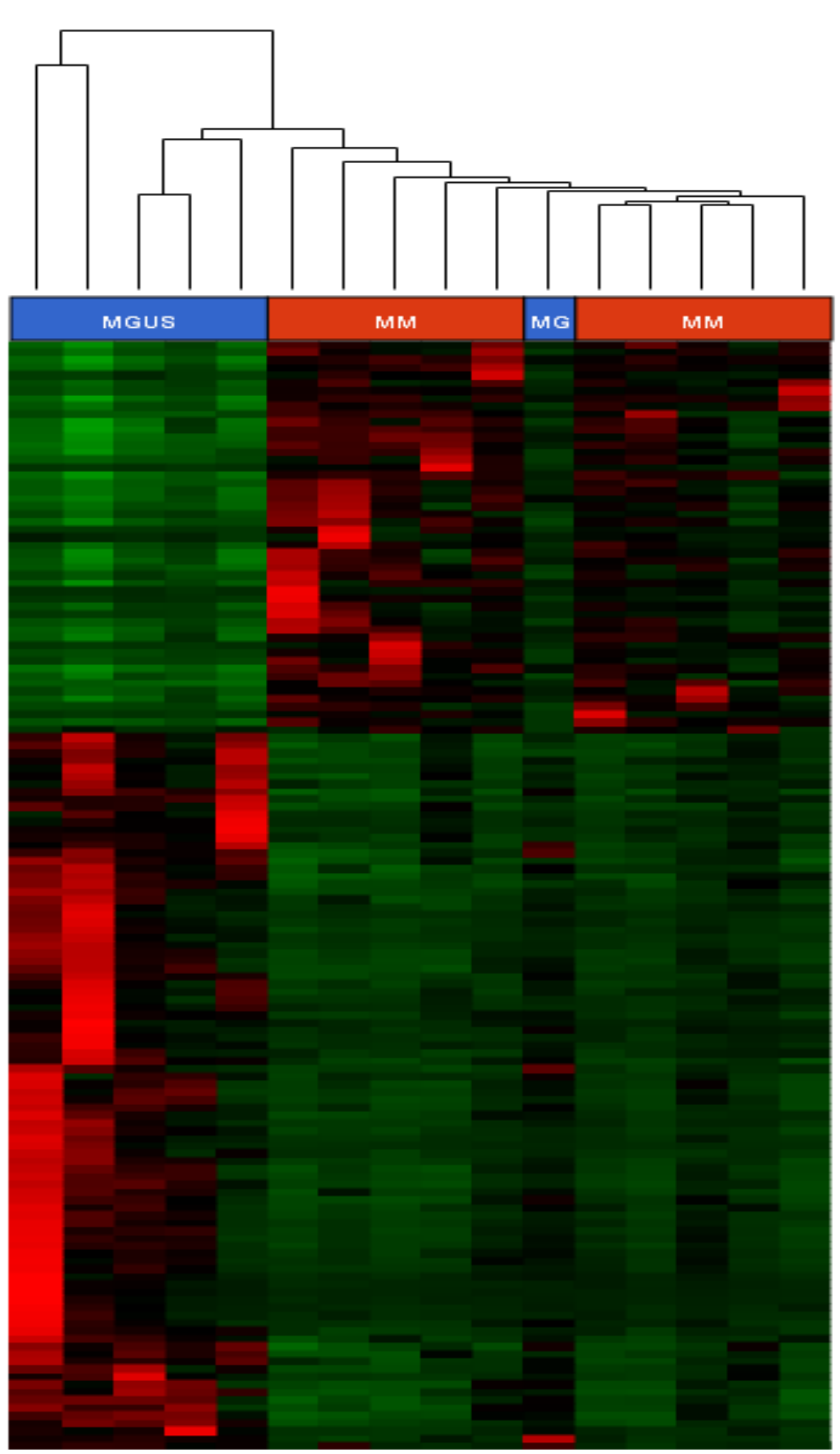




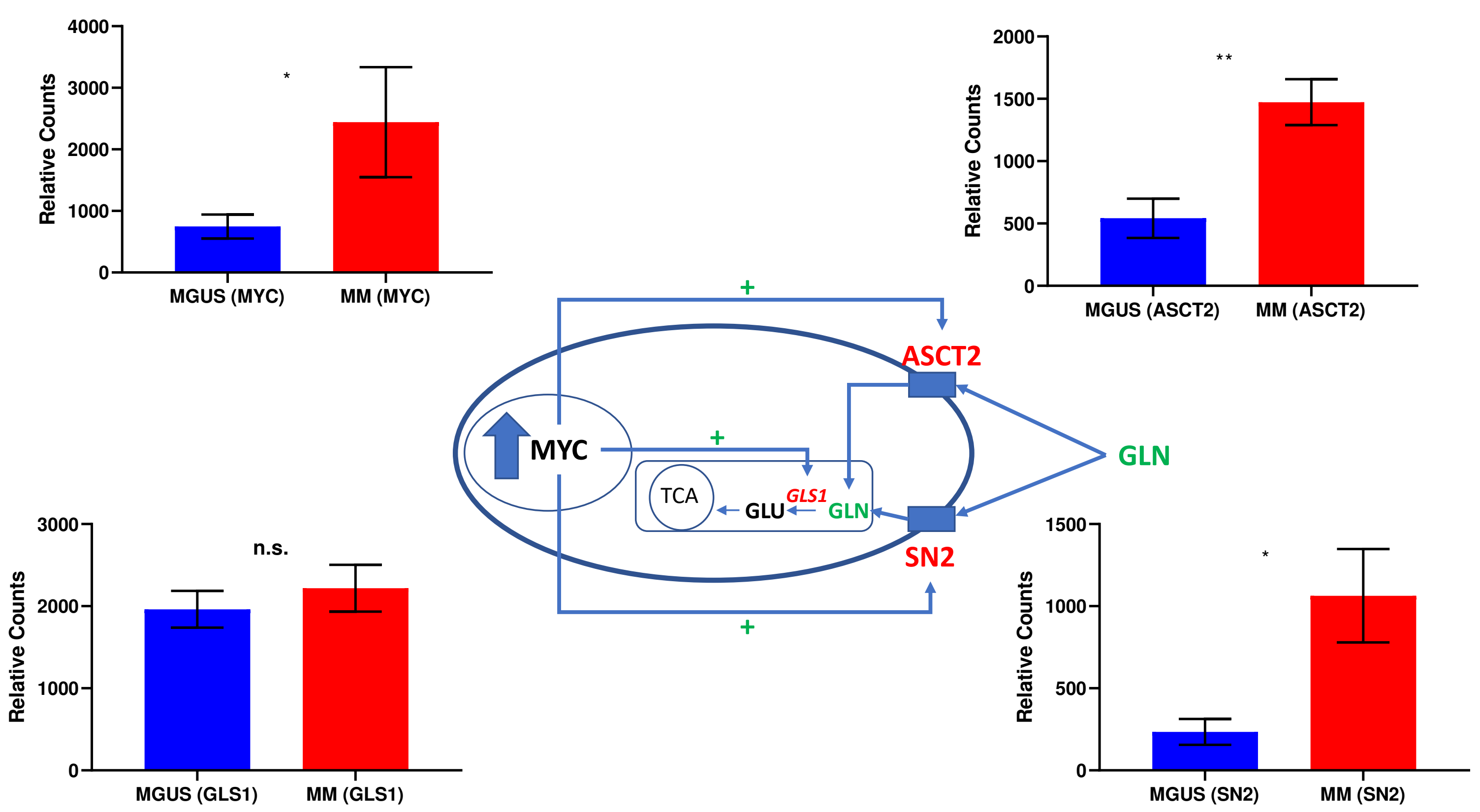

Figure 3B: Relative differences in mRNA expression of c-Myc, GLS, ASCT2 and SN2 between CD138 + cells from MGUS (N = 6) and MM (N = 10) patients in context of their effect on glutamine transport into the cell. 
Glutamine

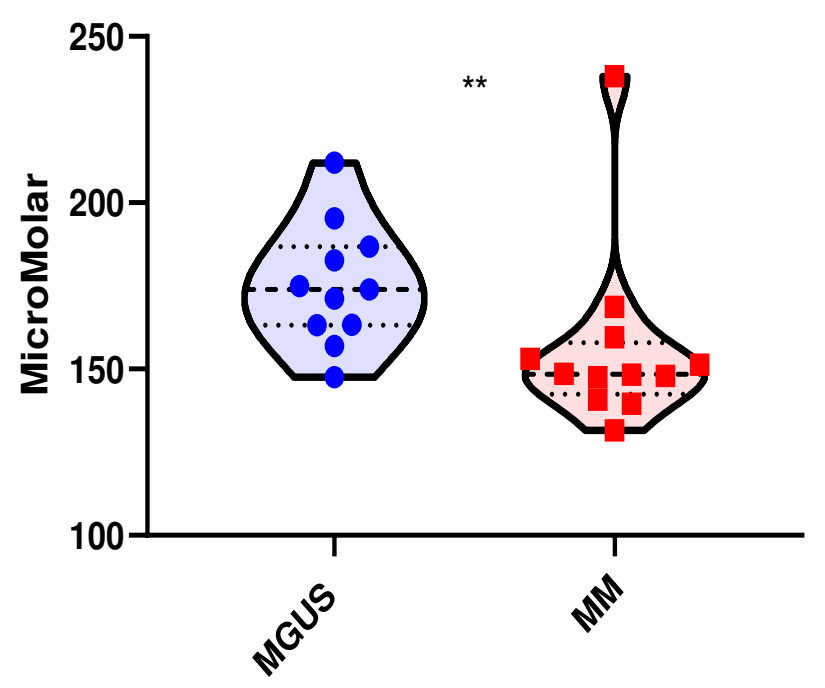

Glutamate

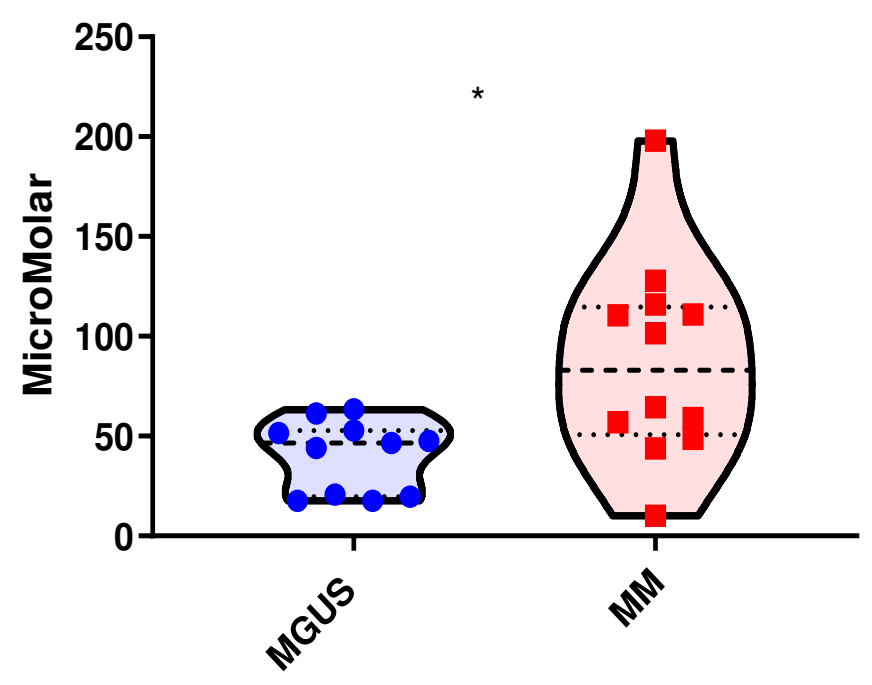

\section{Alpha-ketoglutarate}

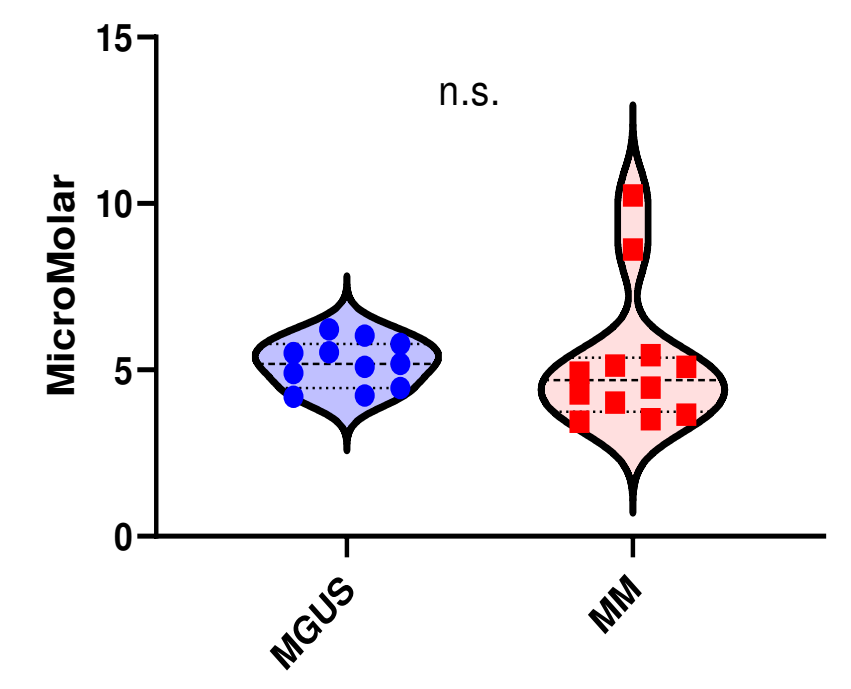

Succinate

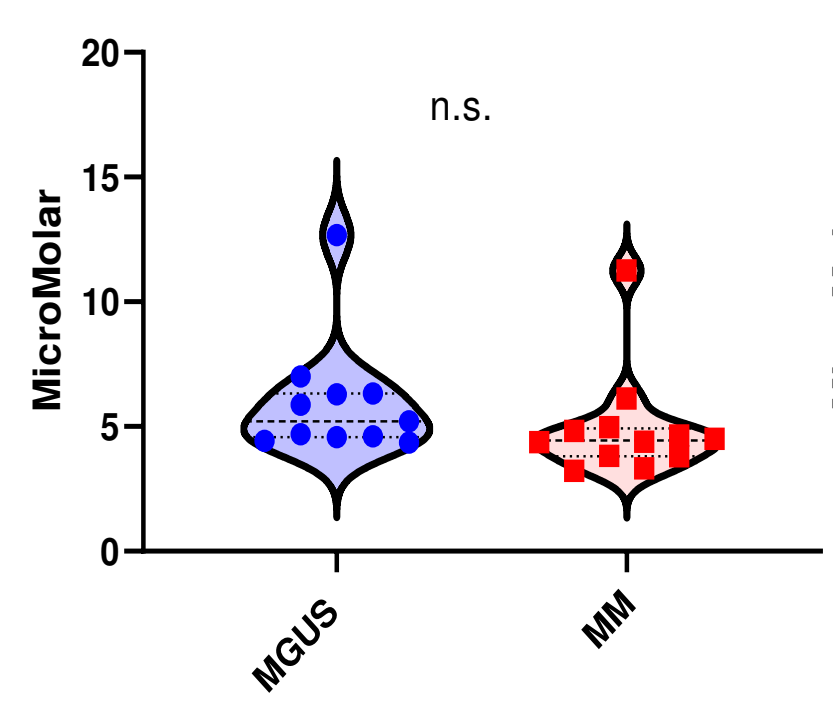

Fumarate

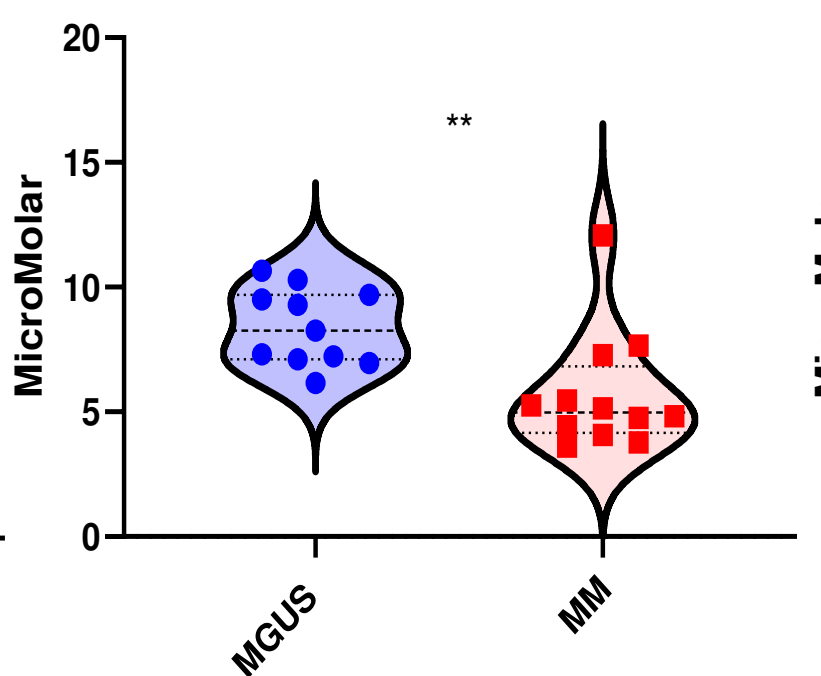

Malate

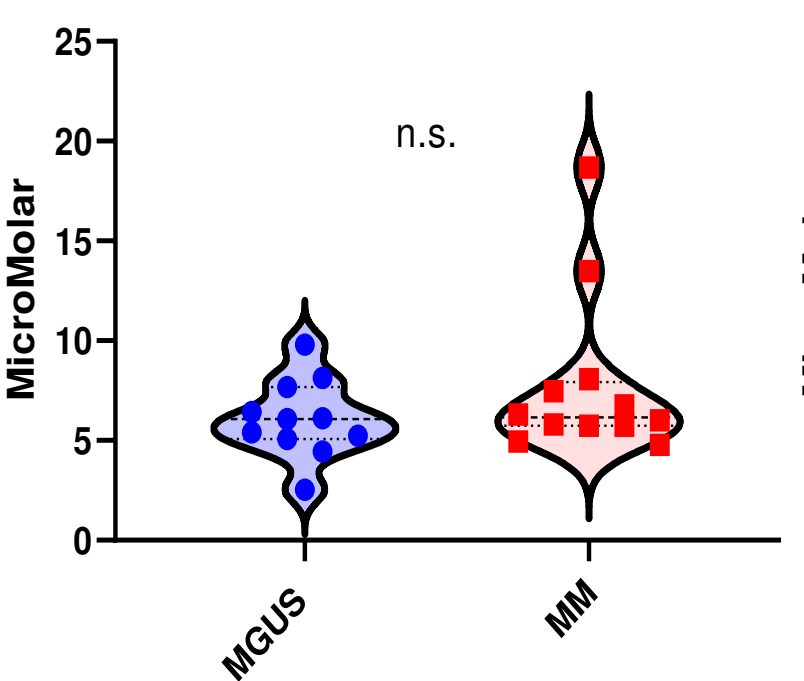

Aspartate

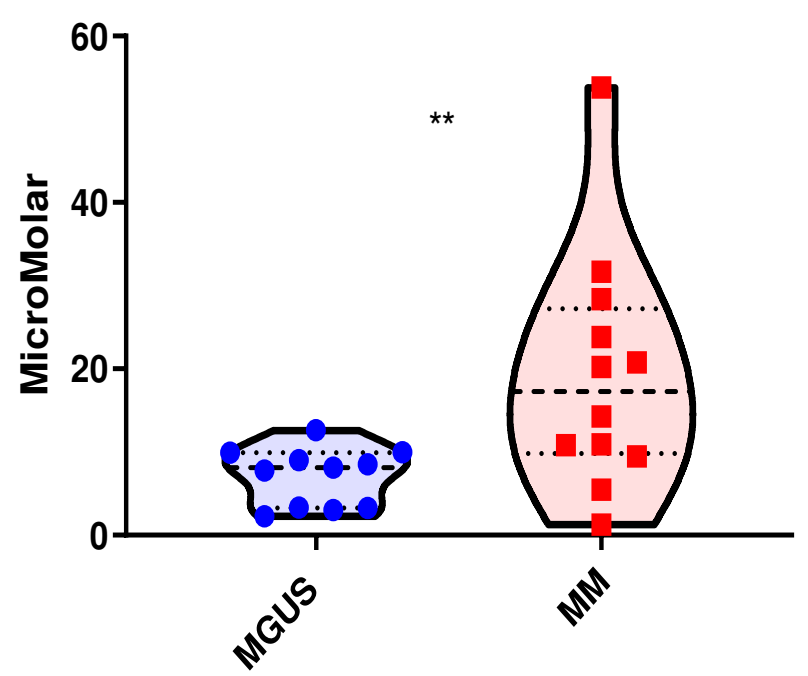

Figure 4A: Violin plots comparing the median concentrations of different TCA metabolites in the bone marrow plasma between MGUS (N = 11) and MM (N = 12) groups. Data was analyzed by Mann-Whitney U test where ${ }^{* * *} \mathrm{p}<0.001,{ }^{* *} \mathrm{p}<0.01,{ }^{*} \mathrm{p}<0.05$, ${ }^{*} \mathrm{p}<0.1$ but $\geq 0.05$, n.s. non-significant. 

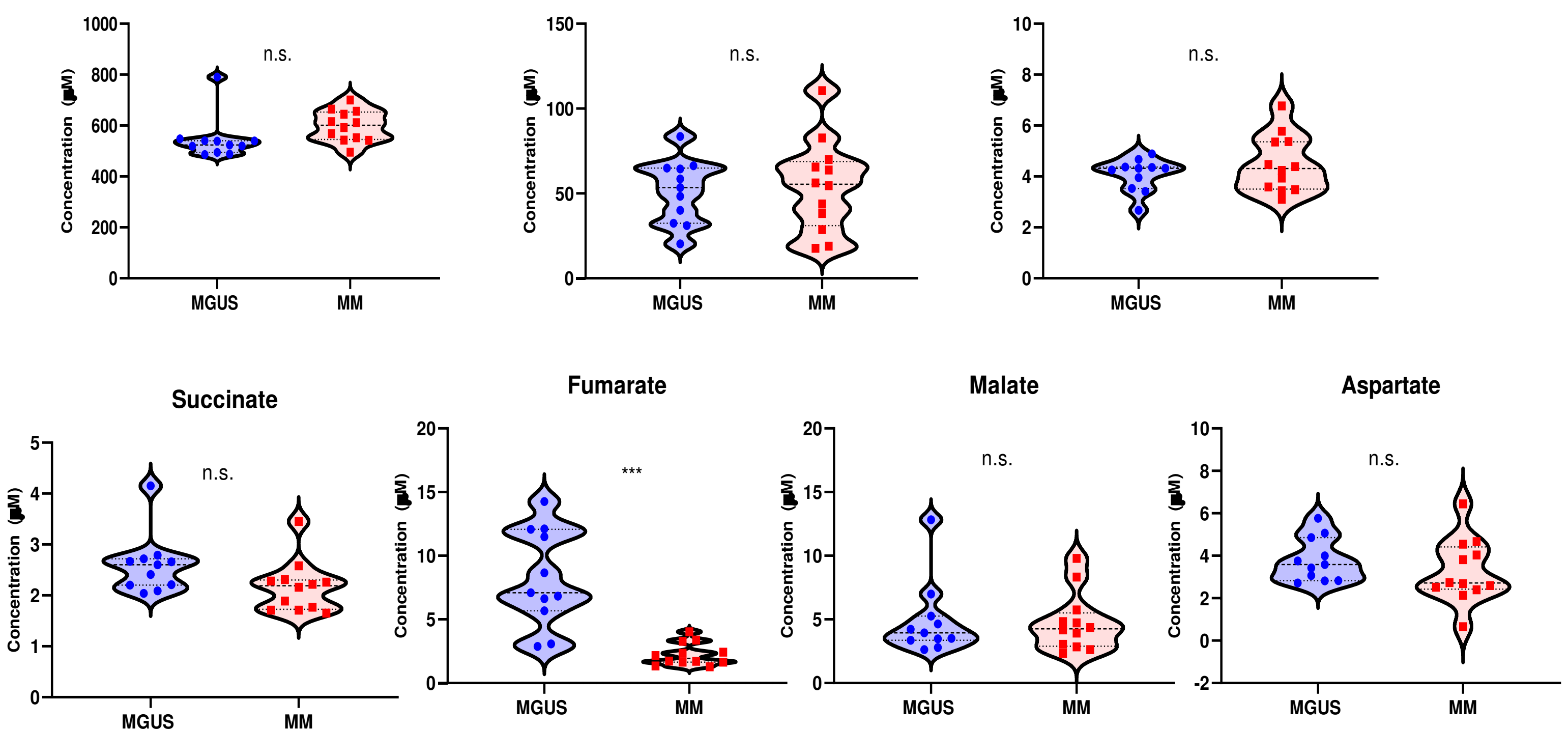

Figure 4B: Violin plots comparing the median concentrations of different TCA metabolites in the peripheral blood plasma between MGUS ( $\mathrm{N}=11$ ) and MM ( $\mathrm{N}$ $=12$ ) groups. Data was analyzed by Mann-Whitney U test where ${ }^{* * *} \mathrm{p}<0.001,{ }^{* *} \mathrm{p}<0.01,{ }^{*} \mathrm{p}<0.05$, ${ }^{*} \mathrm{p}<0.1$ but $\geq 0.05$, n.s. non-significant. 


\section{Glutamate}

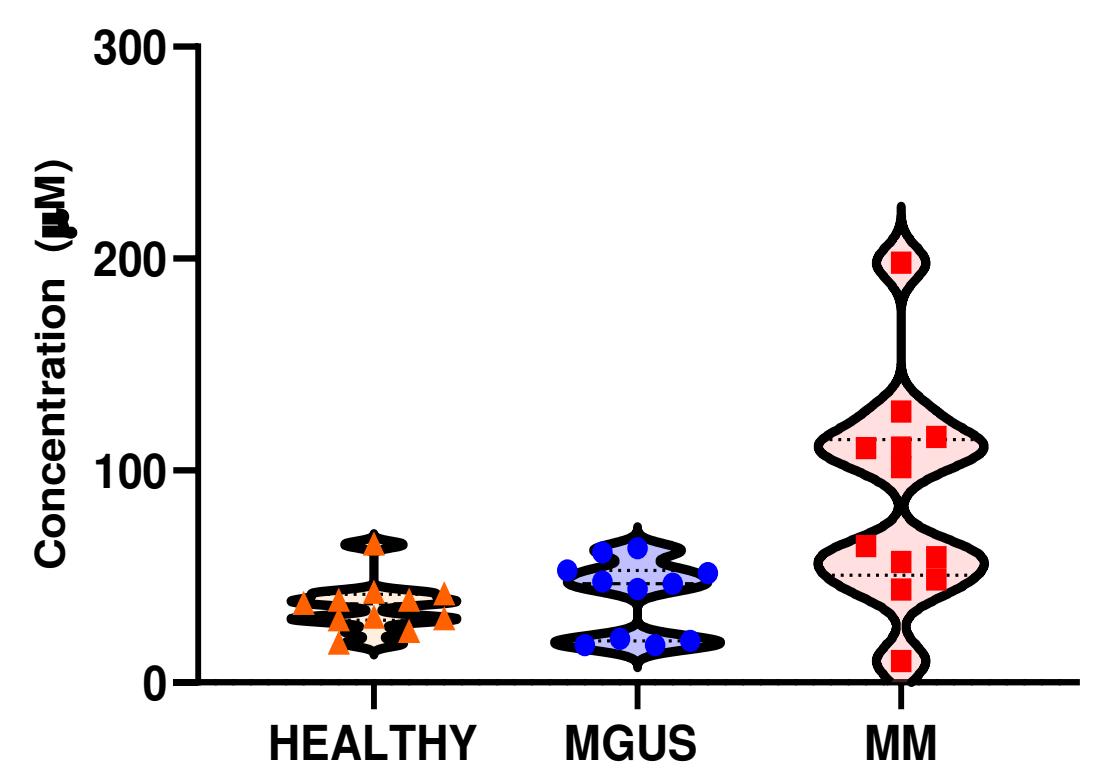

\section{Aspartate}

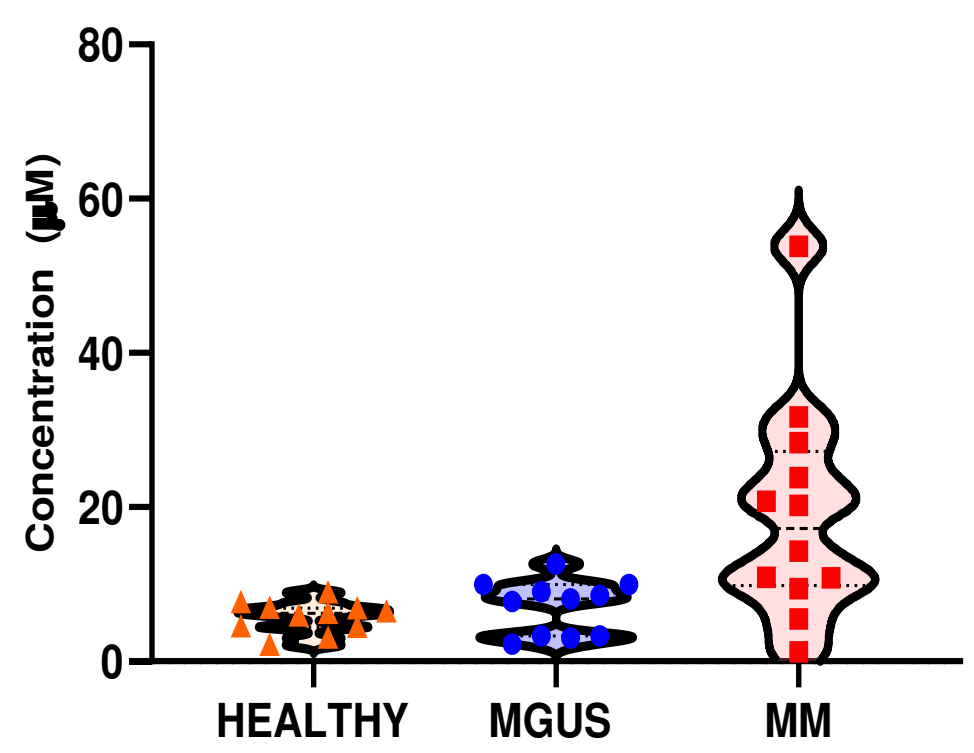

Figure 4C: Violin plots comparing the median concentrations of aspartate and glutamate in the bone marrow plasma between the volunteers ( $\mathrm{N}=7$ ), MGUS ( $=11)$ and MM ( $=12)$ groups. Data was analyzed by Mann-Whitney U test where ${ }^{* * *} \mathrm{p}<0.001,{ }^{* *} \mathrm{p}<0.01,{ }^{*} \mathrm{p}<0.05,{ }^{*} \mathrm{p}<0.1$ but $\geq 0.05$, n.s. non-significant. 


\section{Glutamate}

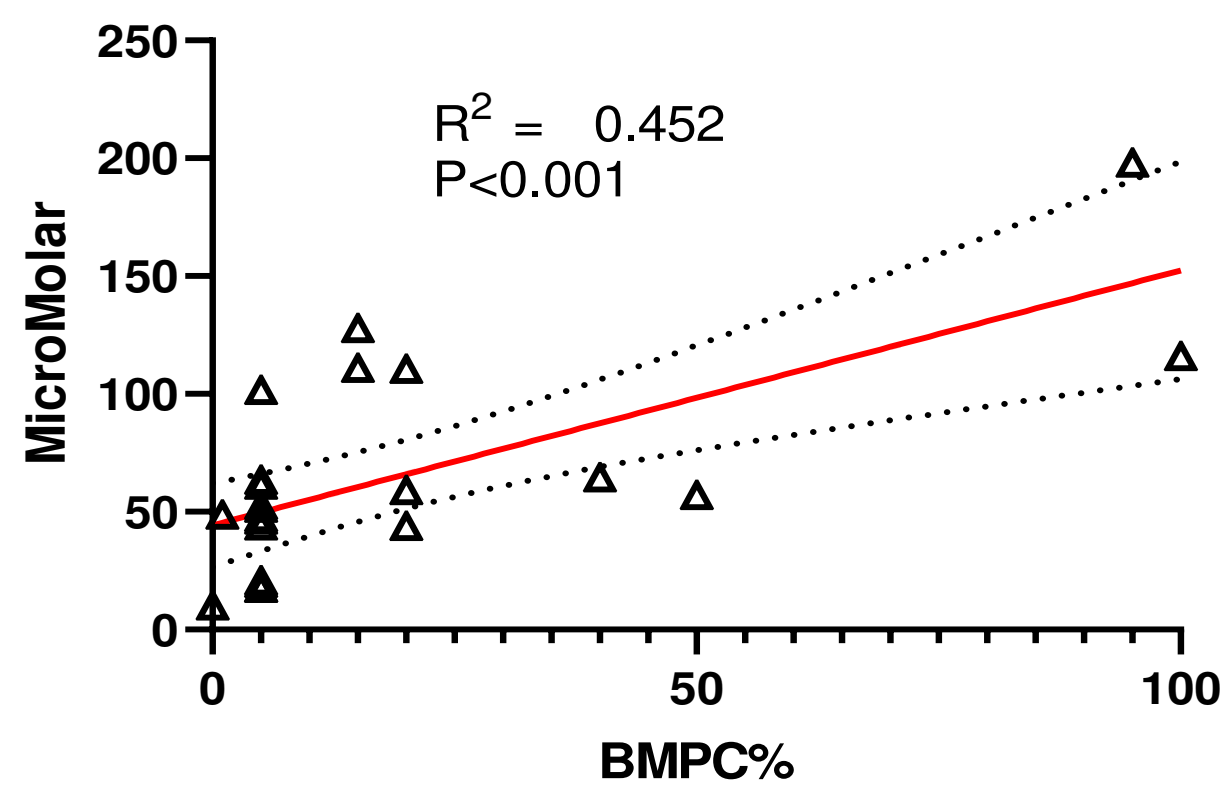

\section{Aspartate}

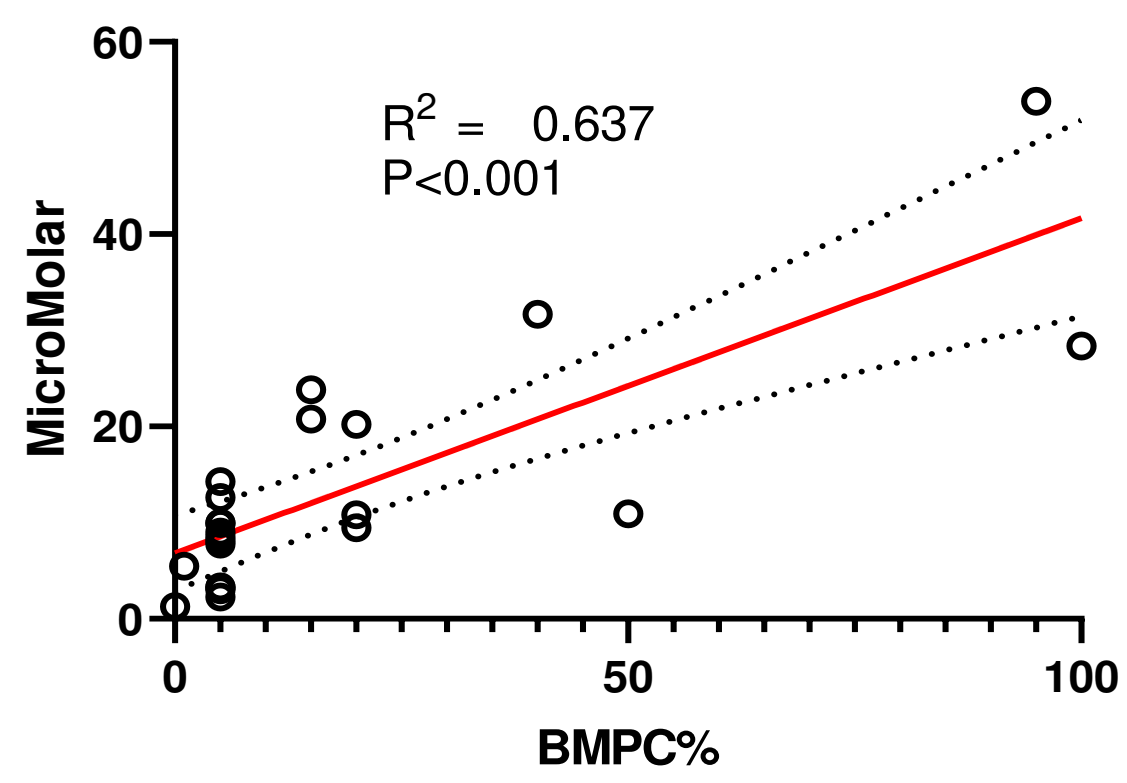

Figure 4D: XY-correlation plots comparing the concentrations of aspartate and glutamate in the bone marrow plasma of patients with MGUS and MM and the percentage of clonal plasma cells in their bone marrow. 
Figure 5C: Graphical visualization of the concentrations of the TCA cycle intermediate such as glutamate, succinate, fumarate, malate and aspartate in the bone marrow plasma of MM patient \#2 with primary plasma cell leukemia and MM patient \#7 with respect to that of the remainder of the MM patients (represented by the mean ----, maximum and minimum ...... values).

\section{Glutamine}

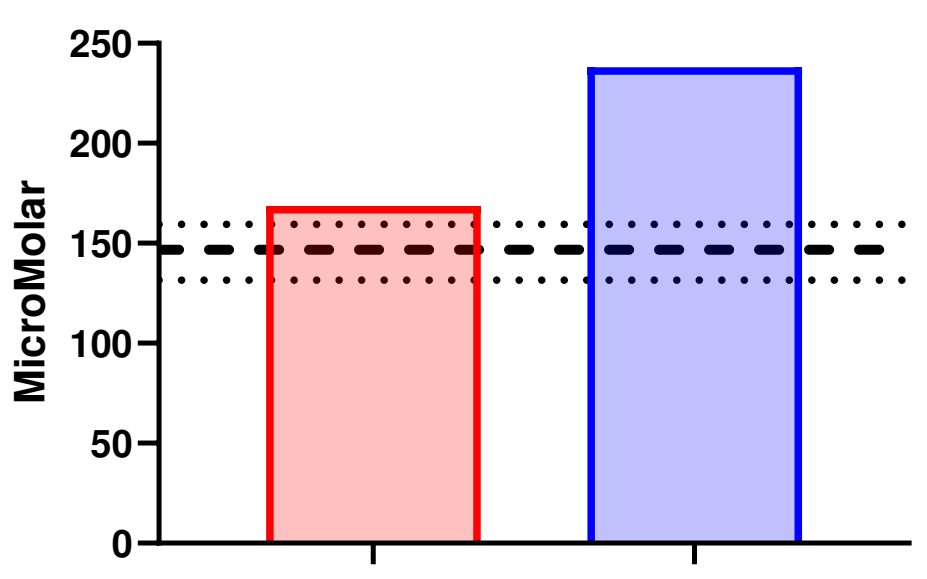

Fumarate

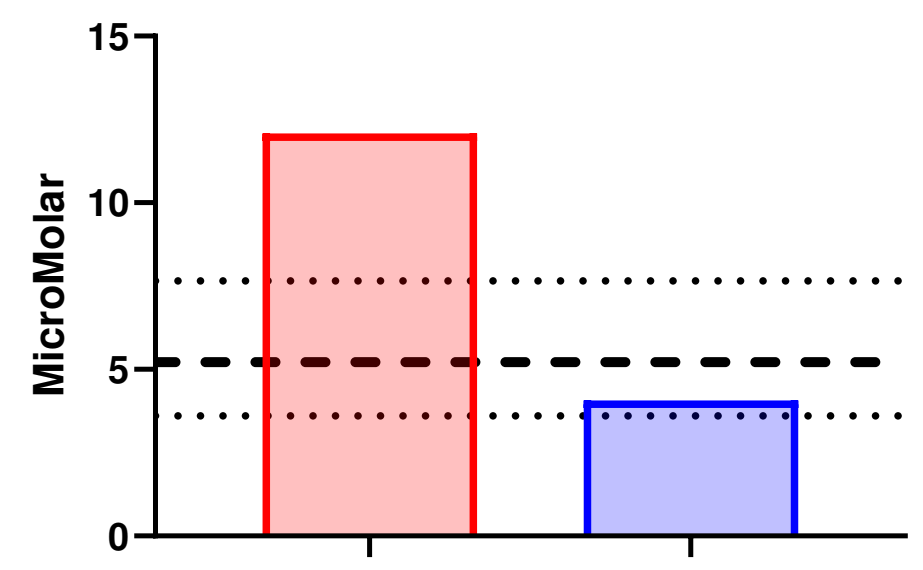

Glutamate

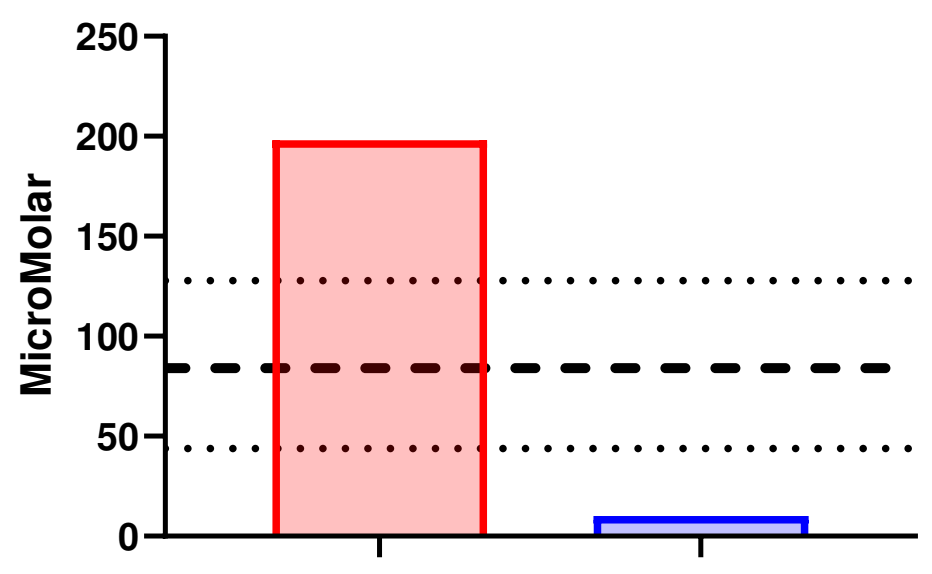

Malate

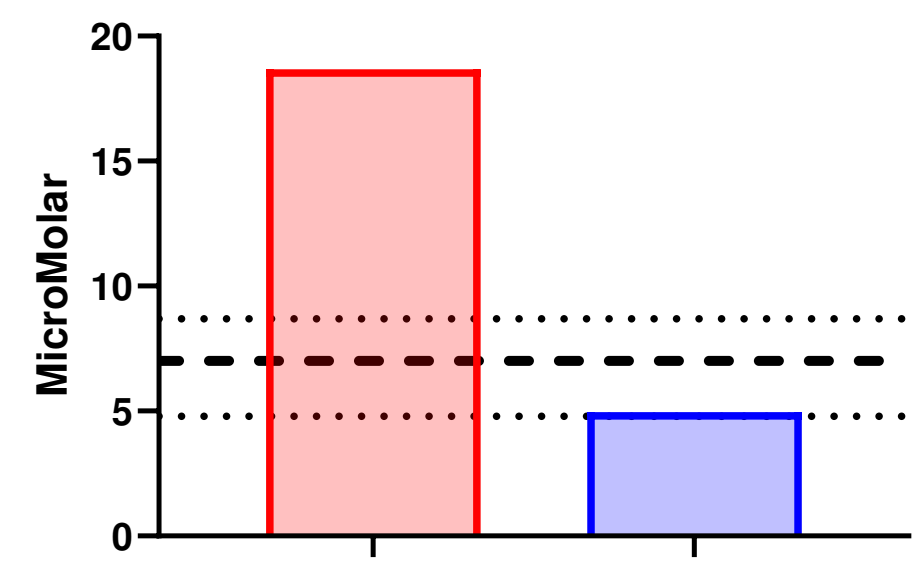

Succinate

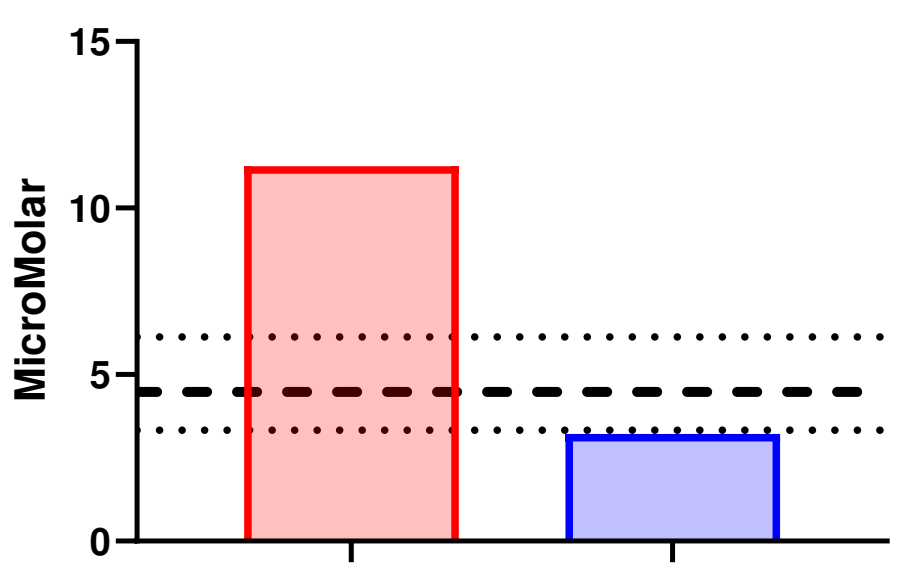

Aspartate

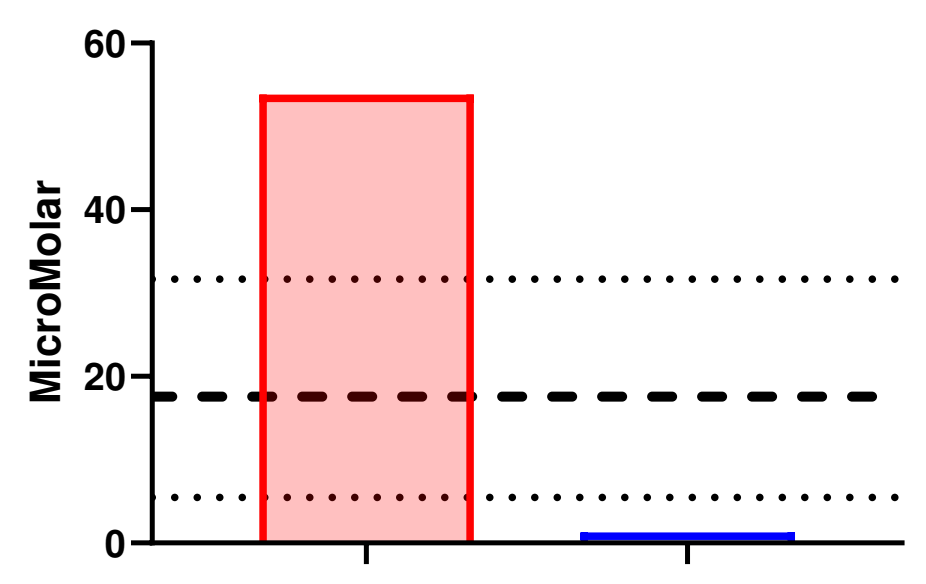




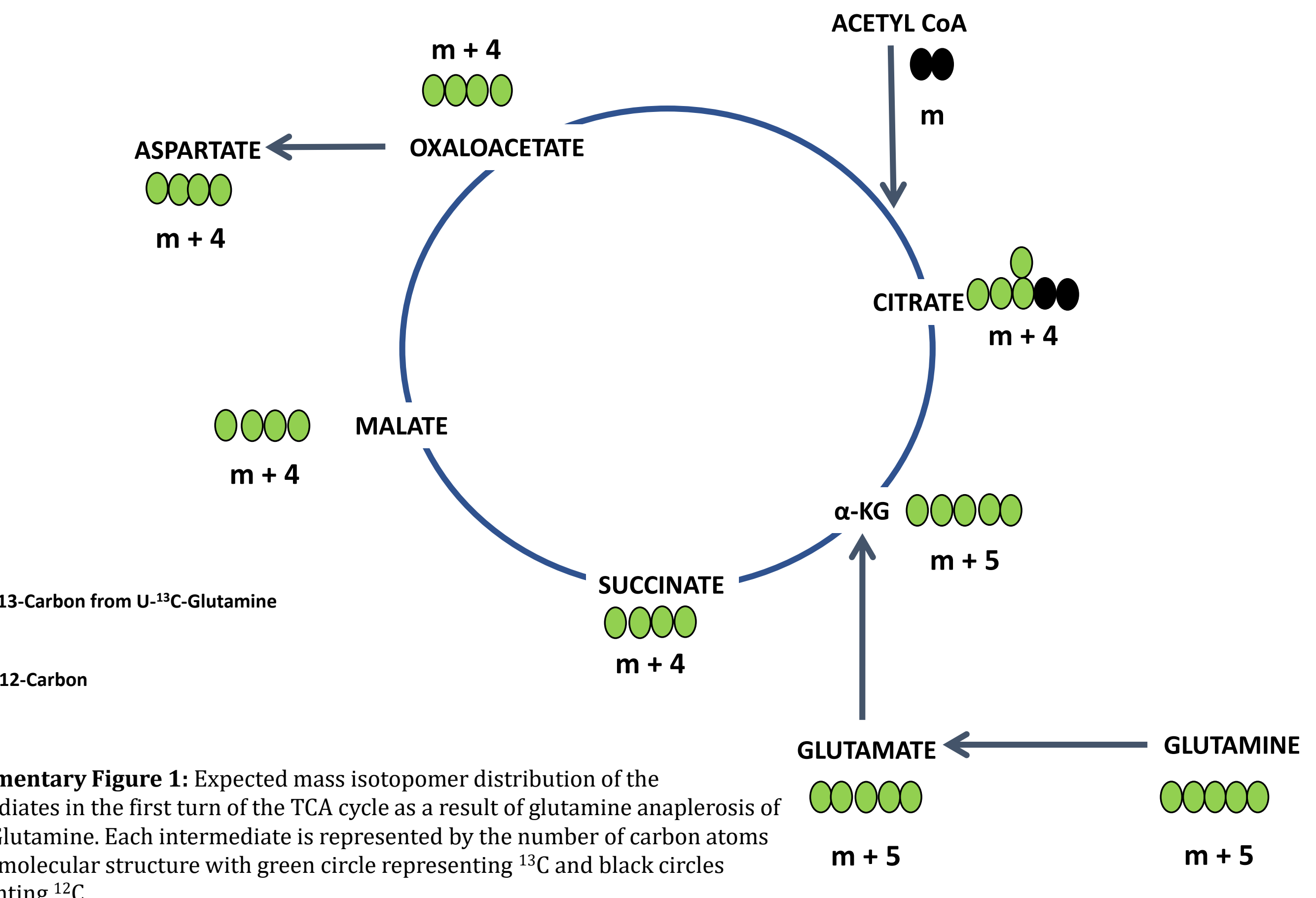

Supplementary Figure 1: Expected mass isotopomer distribution of the intermediates in the first turn of the TCA cycle as a result of glutamine anaplerosis of $\mathrm{U}^{13} \mathrm{C}_{5}$-Glutamine. Each intermediate is represented by the number of carbon atoms in their molecular structure with green circle representing ${ }^{13} \mathrm{C}$ and black circles representing ${ }^{12} \mathrm{C}$. 


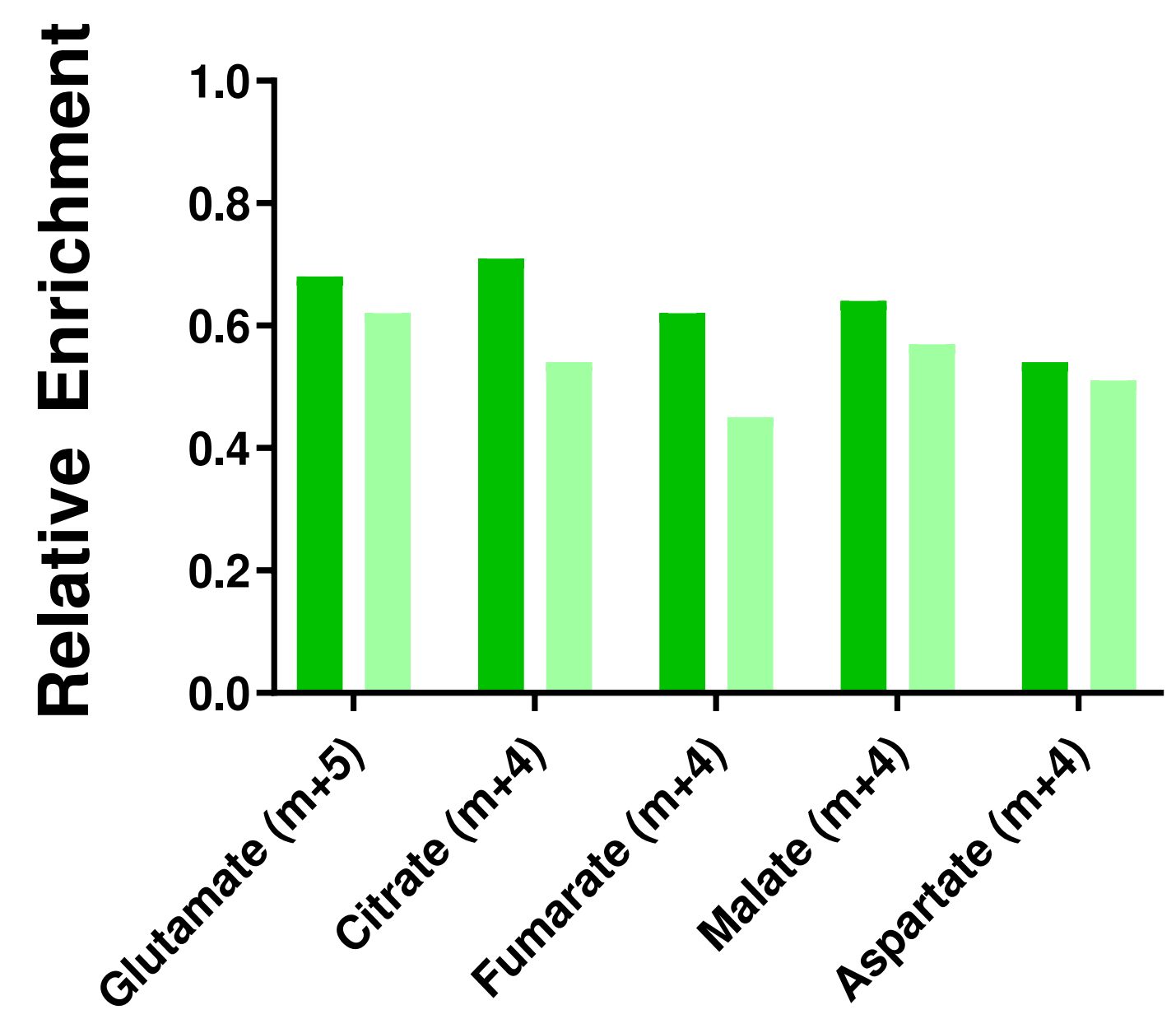

Supplementary Figure 2: The percent intracellular isotopomer distribution of metabolites from the first turn of the TCA cycle in RPMI-8226 and MM1S human myeloma cell lines relative to the $\mathrm{U}^{13} \mathrm{C}$-glutamine enrichment in the cell culture media. 


\section{Figures}

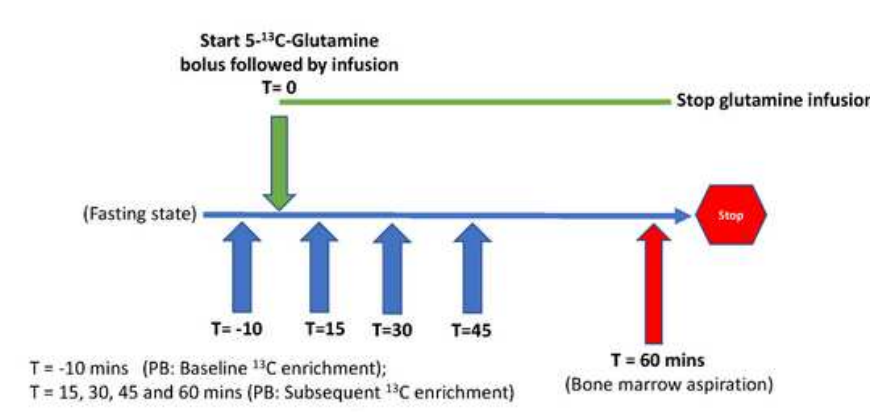

A

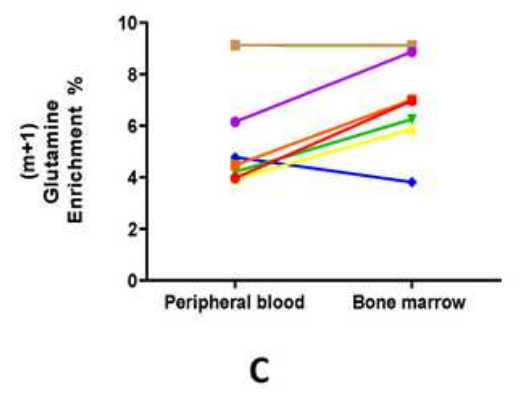

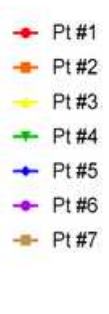

$\sqrt{2}$

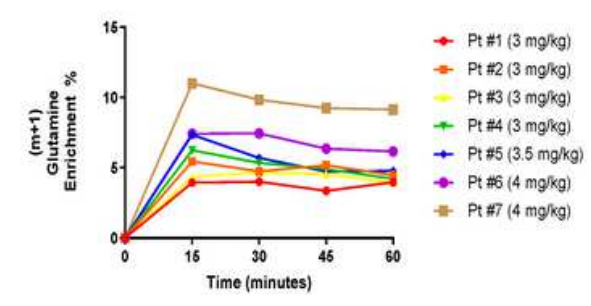

B

\section{Figure 1}

Figure 1A: Timeline of procedures/evaluations performed on the volunteers during the study day. PB: peripheral blood assessment. Figure 1B: Plasma glutamine enrichment during the 5-13C-glutamine infusion in each of the volunteers $(\mathrm{N}=7)$. Figure $1 \mathrm{C}$ : Glutamine enrichment in paired bone marrow and peripheral blood plasma after 60 minutes of the 5-13Cglutamine infusion from each of the volunteers $(\mathrm{N}$ $=7)$. Figure 1D: Comparison of mean 13C fractional enrichment of TCA cycle intermediates in CD138+ and CD138- cells from the bone marrows of volunteers $(\mathrm{N}=3))$ relative to the glutamine enrichment in their marrow plasma . Error bars represent SEM. n.s. is non-significant by paired t-test. 


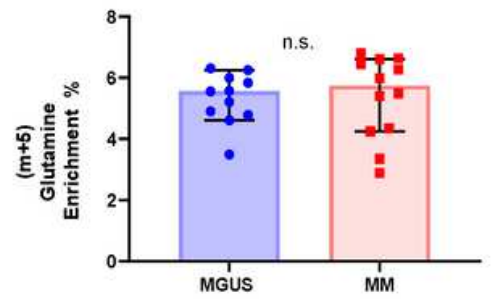

A
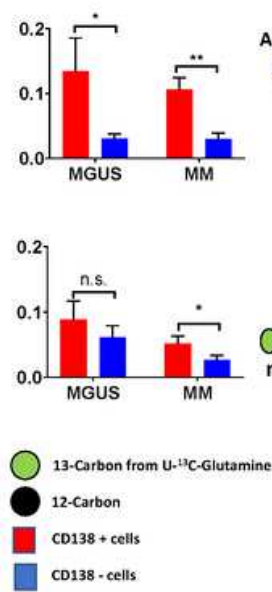

CD138 - cells

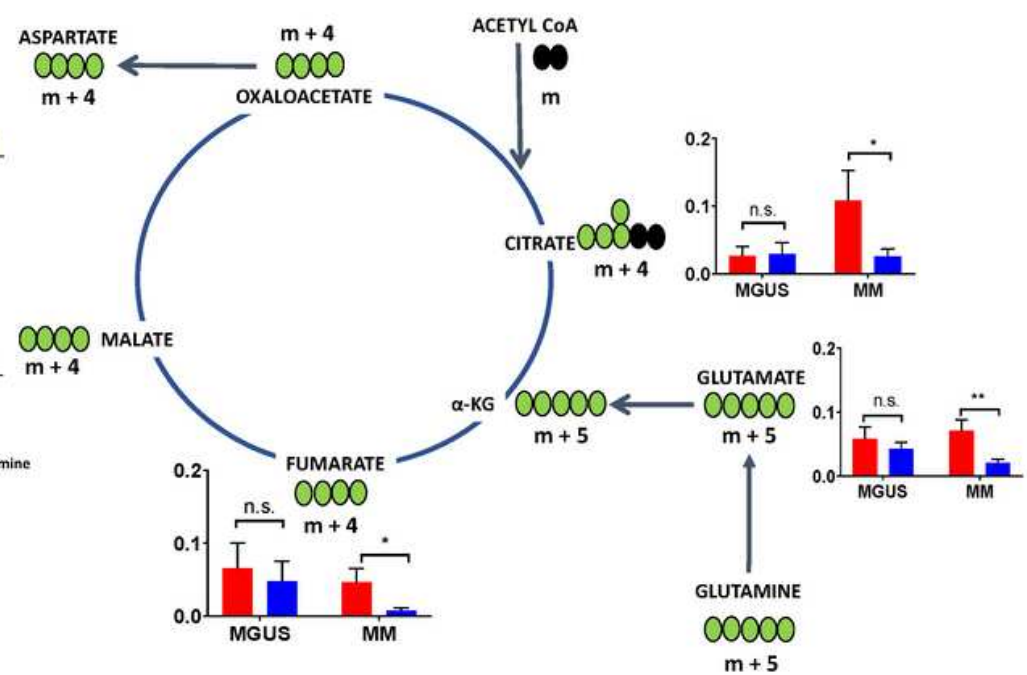

B
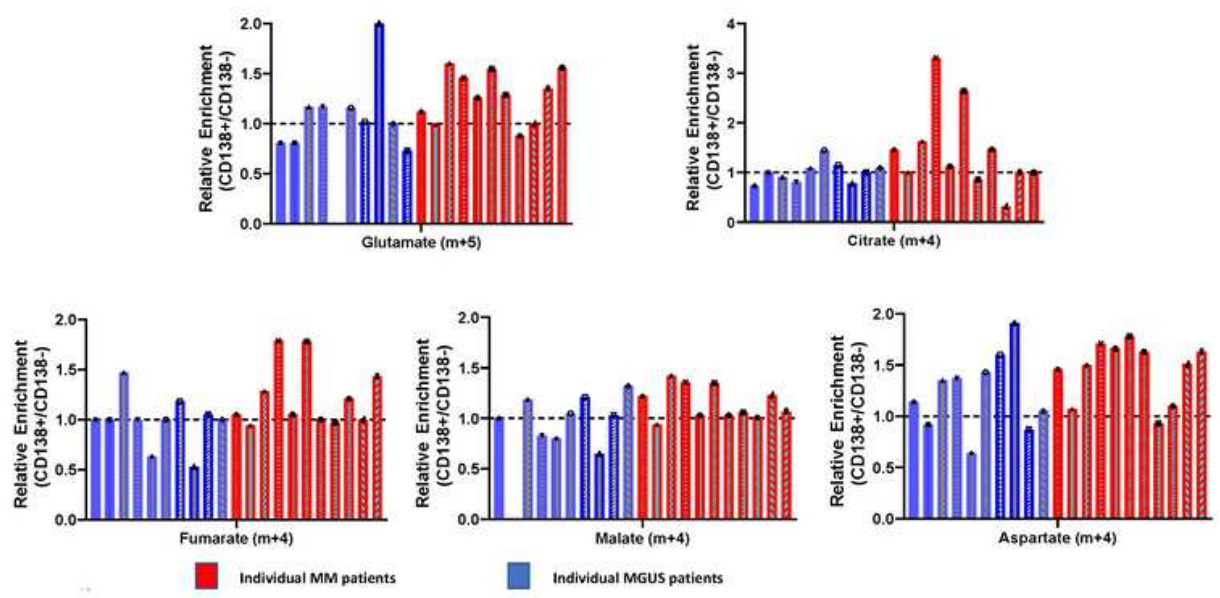

C

\section{Figure 2}

A: Glutamine enrichment in bone marrow plasma after 60 minutes of the [13C5]-glutamine infusion in patients with MGUS $(\mathrm{N}=11)$ and MM $(\mathrm{N}=12)$. Error bars represent SEM. n.s. is non-significant by unpaired t-test. B: Comparison of mean 13C fractional enrichment of TCA cycle intermediates in CD138 + and CD138 - cells from the bone marrows of MGUS $(N=10)$ and MM $(N=11)$ relative to the glutamine enrichment in their marrow plasma. Error bars represent SEM. n.s. is non-significant, * $p<0.05, * * p<$ 0.01 and ${ }^{* * *} p<0.001$ by paired t-test. C: $13 \mathrm{C}$ fractional enrichment of intermediate upon the first turn of the TCA cycle (CD138+/CD138-) from each MGUS $(\mathrm{N}=10)$ and MM $(\mathrm{N}=11)$ patient. MGUS\#5 and MGUS\#2 were unable to have their glutamate $(\mathrm{m}+5)$ and malate $(\mathrm{m}+2)$ assessed due to technical errors during GC-MS assessment and have been not reported. 


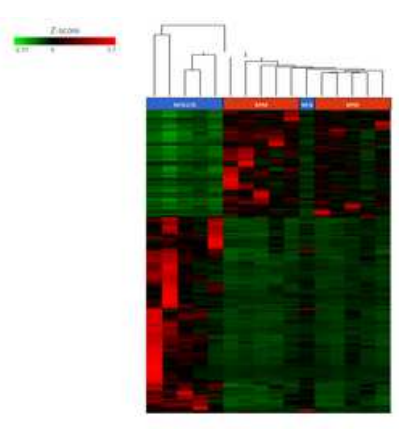

A
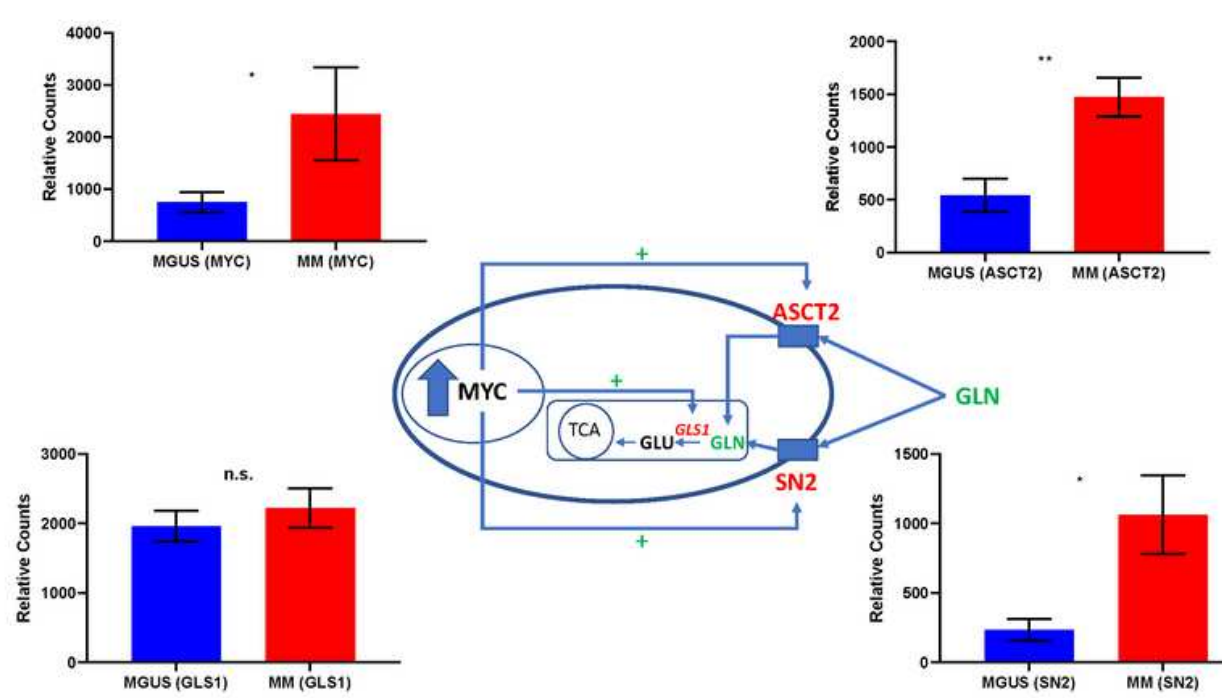

B

\section{Figure 3}

A: Hierarchical clustering analysis on the overall differential expression of genes between MGUS $(\mathrm{N}=6)$ and MM $(\mathrm{N}=10)$ patients. 3B: Relative differences in mRNA expression of c-Myc, GLS, ASCT2 and SN2 between CD138 + cells from MGUS $(N=6)$ and MM $(N=10)$ patients in context of their effect on glutamine transport into the cell.
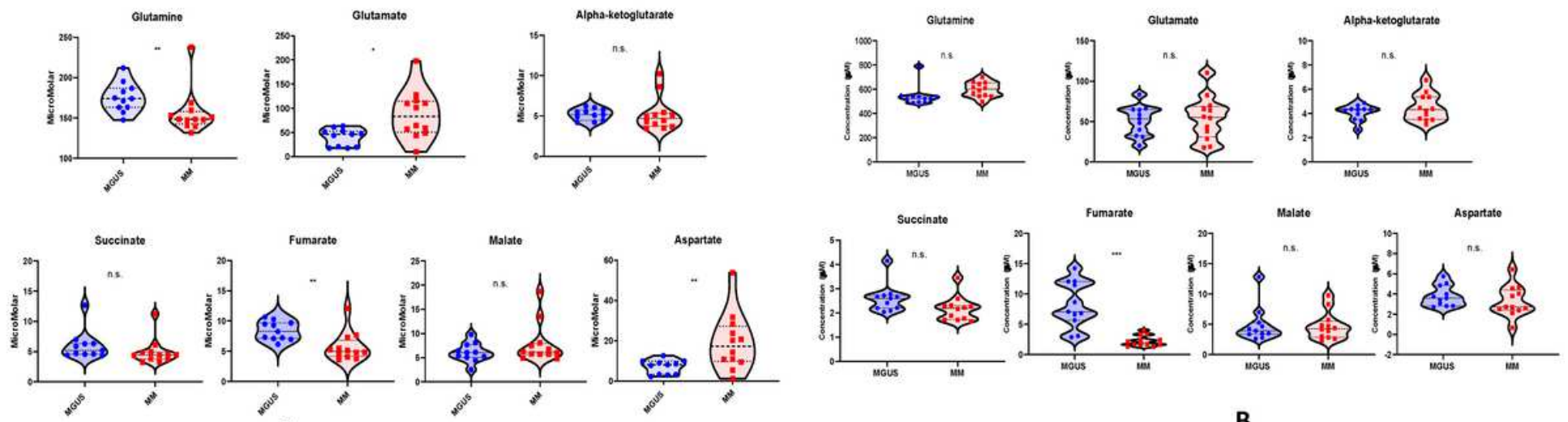

A
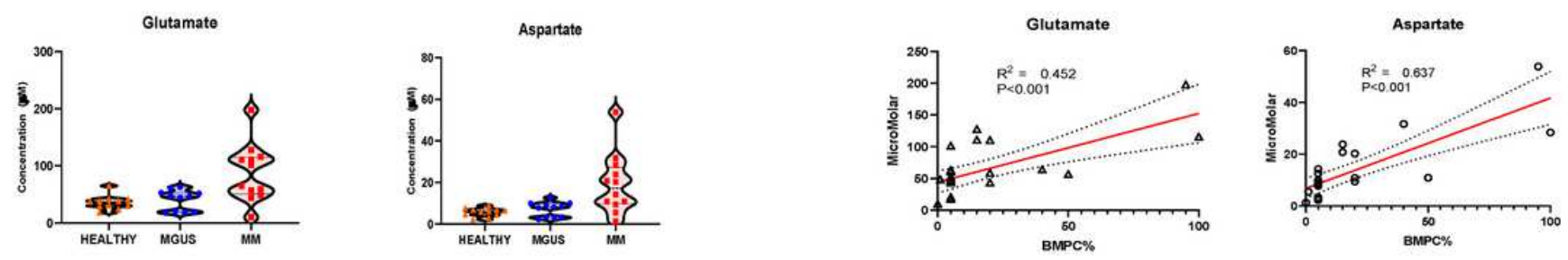

C

D

\section{Figure 4}

A: Violin plots comparing the median concentrations of different TCA metabolites in the bone marrow plasma between MGUS $(\mathrm{N}=11)$ and MM $(\mathrm{N}=12)$ groups. Data was analyzed by Mann-Whitney $\mathrm{U}$ test 
where ${ }^{\star \star *} p<0.001,{ }^{\star \star} p<0.01,{ }^{\star} p<0.05, \# p<0.1$ but $>0.05$, n.s. non-significant. B: Violin plots comparing the median concentrations of different TCA metabolites in the peripheral blood plasma between MGUS $(N=11)$ and MM $(N=12)$ groups. Data was analyzed by Mann-Whitney $U$ test where $* * * p$ $<0.001,{ }^{* \star} p<0.01,{ }^{*} p<0.05, \# p<0.1$ but $>0.05$, n.s. non-significant. 4C: Violin plots comparing the median concentrations of aspartate and glutamate in the bone marrow plasma between the volunteers ( $\mathrm{N}$ $=7)$, MGUS $(\mathrm{N}=11)$ and MM $(\mathrm{N}=12)$ groups. Data was analyzed by Mann-Whitney $U$ test where $* \star \star p<$ $0.001,{ }^{*} p<0.01,{ }^{*} p<0.05, \# p<0.1$ but $>0.05$, n.s. non-significant. $4 \mathrm{D}$ : $X Y$-correlation plots comparing the concentrations of aspartate and glutamate in the bone marrow plasma of patients with MGUS and $\mathrm{MM}$ and the percentage of clonal plasma cells in their bone marrow.

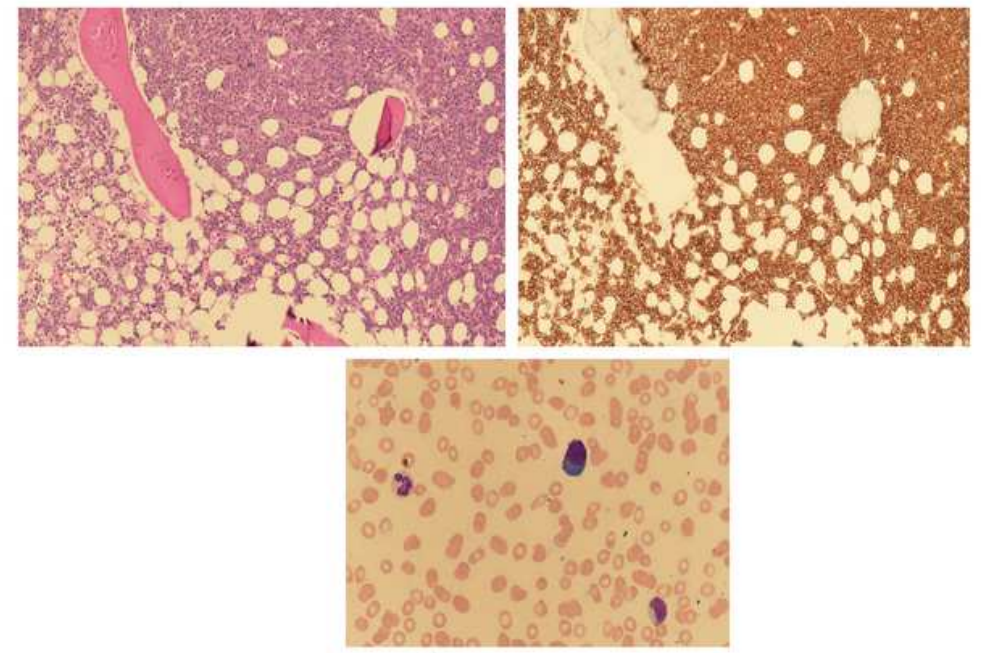

A
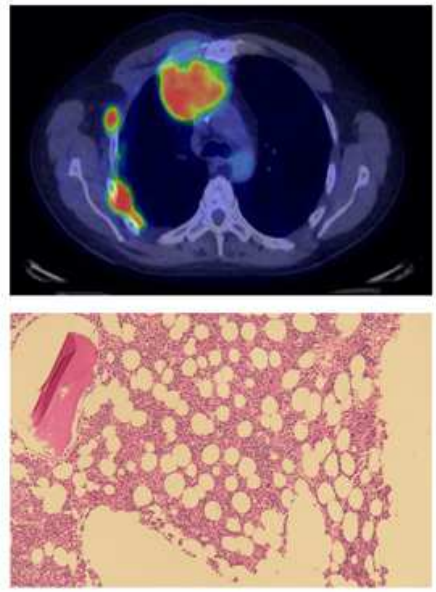
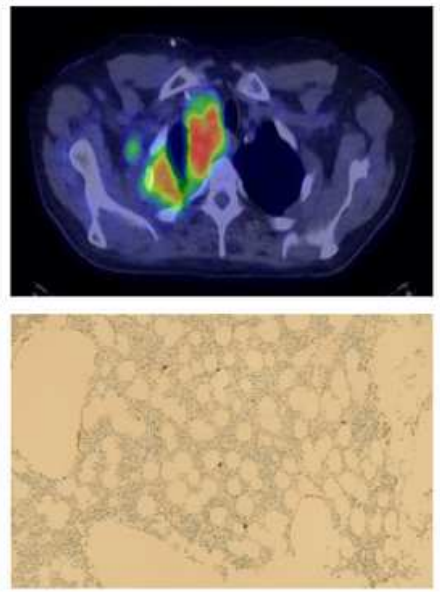

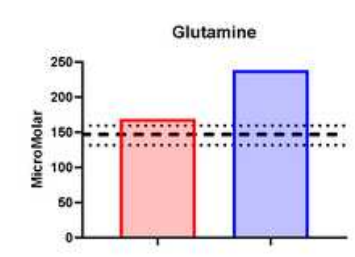

Fumarate

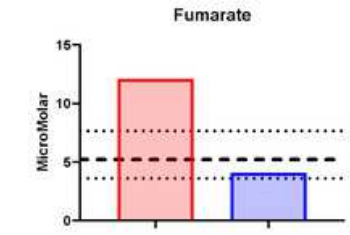

..... Mean $(\min -\max )$ concentration of remainder of $\mathrm{MM}$ patients

C

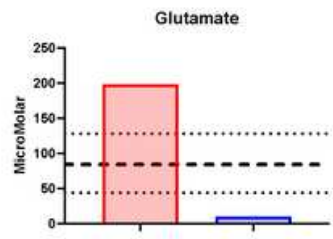

Malate

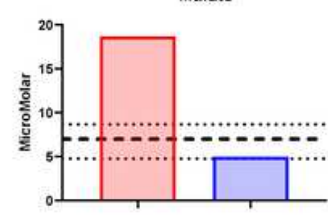

$\square \mathrm{pPCL}$

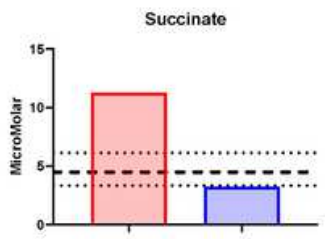

Aspartate

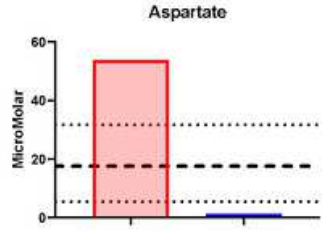

$\mathrm{MM}$ w/ no marrow involvement

\section{Figure 5}

A: Immunohistochemical staining of the bone marrow for CD138+ clonal plasma cells in MM patient \#2 with primary plasma cell leukemia as well as peripheral smear evaluation demonstrating the presence of circulating plasma cells. B: Positron Emission Tomography - Computed Tomography (PET/CT) demonstrating the presence of a large plasmacytoma in the right chest wall as well as immunohistochemical staining of the bone marrow for CD138 + clonal plasma cells in MM patient \#7 with no marrow involvement. C: Graphical visualization of the concentrations of the TCA cycle 
intermediate such as glutamate, succinate, fumarate, malate and aspartate in the bone marrow plasma of MM patient \#2 with primary plasma cell leukemia and MM patient \#7 with respect to that of the remainder of the MM patients (represented by the mean --, maximum and minimum ...... values). 